\title{
Uncertain population futures: Critical reflections on the IHME Scenarios of future fertility, mortality, migration and population trends from 2017 to 2100
}

Stuart Gietel-Basten* and Tomáš Sobotka**

* Division of Social Science and Division of Public Policy, The Hong Kong University of Science and Technology, Clear Water Bay, Hong Kong SAR, People's Republic of China. Email: <sgb@ust.hk>

** Wittgenstein Centre for Demography and Global Human Capital (Univ. Vienna, IIASA, VID/ÖAW), Vienna Institute of Demography/Austrian Academy of Sciences, Vordere Zollamtsstraße 3, 1030, Vienna, Austria. Email:

<Tomas.Sobotka@oeaw.ac.at>

SocArXiv

Version 1.2: 23 September 2020

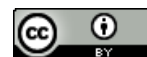




\begin{abstract}
In July 2020 The Lancet published global scenarios of fertility, mortality, migration and population trends from 2017 to 2100 produced by the research team from the Institute for Health Metrics and Evaluation (IHME) (Vollset et al. 2020). These projections, based on a vast amount of data, complex estimates and models, have gained high visibility, also in subsequent media coverage and interviews. Yet, IHME highly publicised population data and scenarios suffer from numerous issues with the underlying data, models and scenarios as well as over-simplistic interpretations of their results. This study aims to substantiate our concerns, spelled out earlier in a letter to the Lancet (Basten, Sobotka et al. 2020), and review major issues and weaknesses with IHME projections and their interpretation. First, we critically examine the data issues, models and their underlying assumptions, including implausible uncertainty intervals and contrasts in predicted trends among countries from broader regions, which often share similar economic and cultural characteristics. Second, we discuss the interpretations of the main findings presented in the discussion part of the paper by Vollset et al. and reflect on the media representation of the projection results. In conclusion, we highlight internal inconsistencies in the IHME modelling approach, which lead to questionable projections for many countries and scenarios.
\end{abstract}




\title{
Uncertain population futures: Critical reflections on the IHME Scenarios of future fertility, mortality, migration and population trends from 2017 to 2100
}

\author{
Stuart Gietel-Basten and Tomáš Sobotka
}

\section{INTRODUCTION}

In July 2020 The Lancet published global scenarios of fertility, mortality, migration and population trends from 2017 to 2100 produced by the research team from the Institute for Health Metrics and Evaluation (IHME) (Vollset et al. 2020). These scenarios were prepared within the broader health data metrics research linked to the Global Burden of Diseases, Injuries, and Risk Factors (GBD) project. The work by Vollset et al is a culmination of the team's earlier research on estimating and assessing population and health data (Murray et al. 2018). In scope, ambition and publicity, it could be argued that the new sets of global projections may overshadow the most widely used global projection scenarios, World Population Prospects (WPP) produced bi-annually by the United Nation's Population Division (UNPD), Department of Economic and Social Affairs (UNPD 2019) as well as other global projections produced by demographers, including the scenarios published by the Wittgenstein Centre for Demography and Global Human Capital (Lutz et al. 2018). ${ }^{1}$

Demographers do not have a monopoly on producing population projections and new scenarios from a prestigious and established organisation like IHME are generally a welcome development. Many governments and international organisations rely on high-quality data and estimates of past and future population trends in their decision-making. IHME and its GBD study have many enviable strengths, including generous resources, a large team of top-level data scientists, economists and epidemiologists and a vast network of collaborators and collaborating institutions (Mahajan 2019). The IHME researchers and collaborators are extremely efficient in producing a vast amount of health and population data and estimates for all countries globally, often using complex models and methods. Yet, the IHME highly publicised population data and scenarios suffer from numerous issues with the underlying data, models and scenarios as well as over-simplistic interpretations of their results. We have summarised our concerns in a short letter to The Lancet, which gained considerable support in the community of population researchers and advocates, of whom more than 170 from all over the world have signed it (Gietel-Basten, Sobotka et al. 2020). ${ }^{2}$ The letter argues that in the IHME scenarios "...some of the baseline data significantly differ from other available data; the migration scenarios

\footnotetext{
${ }^{1}$ Both authors of this paper have participated in a preparation of an earlier round of the Wittgenstein Centre's projection and were responsible for preparing and coordinating the scenarios of fertility in the low-fertility countries (Basten, Sobotka, and Zeman 2014).

${ }^{2}$ The letter, limited to 250 words and submitted on 27 July 2020 (within two weeks of publication of Vollset et al. 2020 paper), was still listed as "being with editor" as of 9 September 2020.
} 
deliver seemingly contradictory results; the fertility scenarios rest upon a highly uncertain future pathway in female education and stretch the observed fertility declines among relatively few recent cohorts of women towards the end of the century; and the mortality assumptions appear extremely conservative in the context of recent research on longevity. Problematic conceptions of 'the workingage population' and measures of ageing are deployed, which do not account for changes in either individual or population level characteristics. The paper adopts an overly simplistic approach to complex social phenomena, such as migration theory and policy, and the conceptual relationship between access to family planning and universal fertility outcomes. Simplistic views of the relationship between shifting population dynamics and climate change, policy, the economy, health systems etc. are repeated in many of the authors' representations to the media." In addition, we believe that the increasing dominance of IHME in the area of health data evaluation, measurement, and production have limited an external scrutiny of their work, and, possibly, have made the IHME researchers less open for a critical discussion of their methods and approaches (Mahajan 2019). Specifically, we reckon that the IHME projections would benefit from a stronger involvement of population researchers, who have an extensive experience with designing, discussing and evaluating population projections.

Here we aim to substantiate our concerns and elaborate our critical view of the IHME scenarios. This contribution is drafted from our perspective as population researchers dealing especially with fertility, migration and broad population trends. It neither represents the views of all the researchers that signed the above-mentioned letter, nor covers the whole universe of models, data, and scenarios used in IHME work. Given the complexity and the massive amount of work involved in IHME scenarios, such a thorough examination is beyond our reach. However, we hope that our commentaries will be followed up by the reflections of other population experts, who will assess other aspects of IHME work. We divide our substantive commentary in two broad parts. First, in Section 2 we critically examine the data issues, models and their underlying assumptions and highlight numerous inconsistencies in the IHME projection scenarios and results. This part focuses most on fertility, which is the key source of a large difference between the IHME projections and the 2019 UN WPP scenarios (Vollset et al. 2020). Second, in Sections 3 and 4 we discuss the interpretations of the main findings presented in the discussion part of the paper by Vollset et al. (pp. 17-19). and reflect on the media representation of the projection results. This was an important and the most visible outcome of the group's work, which focused almost exclusively on the results of the main ("Reference") scenario and the rapid population decline it projects. This singleminded focus on one scenario has been amplified in the interviews by the IHME director, Dr. Christopher Murray (hereafter CM), who stressed the massive population decline and the pace of ageing expected in many countries.

\section{DATA, METHODS AND MECHANISMS IN THE IHME SCENARIOS}

We have identified a variety of issues and concerns about the data, methods, and approaches used in producing IHME population projection scenarios. These issues, detailed below, range from those that could be directly assessed and addressed-such as the assumptions about stable sex ratios at birth in 
countries where they have been distorted-up to broader concerns about inconsistencies and incoherence in the underlying projection framework, which often produce implausible or contradictory results for individual countries and regions. This issue also links to our broader concern about the lack of transparency of IHME work, despite the group's open provision of data and indicators and an explanation of their modelling framework (Supplement to Vollset et al. 2020). Some of the most critical choices in the IHME models, such as imposing a lower limit (of 1 birth per woman) but no upper limit in their fertility scenarios, are briefly mentioned in supplementary Appendix 1, without any reasoning or more detailed substantiation added. This contrasts starkly with the usual practice of scenario building in population research, where critical choices are often discussed, scrutinised and substantiated in detail. ${ }^{3}$

This section looks first at the underlying data in the base year (2017) of the IHME scenarios, then scrutinises in detail the scenarios of fertility, mortality and migration as well as more specific analytical and modelling choices. Finally, we discuss broader issues pertaining to scenarios building and why we argue that in combination the IHME projection exercise does not hold together well.

\subsection{Baseline data for 2017}

The signature philosophy of the IHME work is to generate own (GBD) estimates of data and indicators for almost any issue and phenomenon analysed. The same applies for the data used in their projection exercise: although global estimates of all basic population and demographic indicators for all countries and years since 1950 have been traditionally produced by the UNPD (see UNDP 2019a), the GBD/IHME group has estimated its own universe of annual data and indicators on fertility, mortality, migration and population for 195 countries and territories covering the period of 1950 to 2017 (Murray et al. 2018), which are based on a vast amount of census and population registry data. Whereas the UN data are produced as point estimates and in countries with high quality vital statistics they correspond with the data produced by national statistical offices, the IHME data are partly model-based and may therefore differ from the officially reported data by quite a wide margin. This is especially the case for the most recent years: IHME's population data and demographic indicators for 2017-i.e., the base year of their projection scenarios-are therefore characterised by two peculiarities when scrutinised from a perspective of countries with high-quality population data. First, the IHME team often provides their indicators with a wide margin of uncertainty for countries with high-quality and complete coverage of population and vital statistics data. Second, even with these wide uncertainty margins, the IHME $95 \%$ uncertainty range of estimates for 2017 often does not match the officially reported data in some countries with high-quality population statistics.

\footnotetext{
${ }^{3}$ For instance, the set of the Wittgenstein Centre's global projection scenarios produced in 2014 was backed up by a global survey of population experts on the forces affecting future fertility, mortality and migration, as well as additional reviews, analytical work and modelling exercises that were documented in detail in the volume edited by Lutz, Butz and KC (2014).
} 
Remarkably, the initial estimated uncertainty by IHME could be smaller in some of the countries with incomplete population estimates (often due to high rates of outmigration or due to incomplete population statistics) than in the countries with excellent data quality. For instance, the estimated 95\% confidence interval (Cl_95) for the Total Fertility Rate in Bosnia and Herzegovina in 2017 (1.17 to 1.36) is lower in absolute and relative terms than that for Finland (1.47 to 1.83). ${ }^{4}$

In many cases, the magnitude of the mismatch between IHME and official statistics is remarkable. In the Republic of Korea, which currently has the lowest period total fertility rate globally (0.92 in 2019; KOSIS 2020), the IHME estimate for 2017, of the TFR at 1.24 (Cl_95 at 1.18 to 1.29), is by almost $18 \%$ above the officially reported TFR for 2017 by the Statistics Korea (1.052; KOSIS 2020). ${ }^{5}$ This is not a rare case-even for a large country like Germany, the IHME estimate of the TFR in 2017 (Cl_95 from 1.241 to 1.569) narrowly failed to match the officially reported TFR of 1.57. These were not exceptional cases-the IHME range estimate of the Cl_95 in the TFR for 2017 also did not match the officially reported TFRs in Finland, Malta, New Zealand, Turkey and many other countries (see Figure 1 for a comparison of the official TFR and its IHME range estimate in selected countries in Europe and Asia). It is surprising that the vast team of IHME researchers and collaborators ${ }^{6}$ have not attempted to update or correct some of these data since the time they were first estimated.

Overall, for most regions there is no evidence of a systematic downward or upward bias in the IHME data: some of the estimates that are too low (Cyprus, Czechia, Malta, Germany) are "compensated for" by other estimates that appear too high (Republic of Korea, Finland, New Zealand). However, there is an important exception: in Africa, the region which will be key for the pace of global fertility decline in the next decades, and where the data are often more patchy and uncertain than in other regions, the IHME estimates of the TFR in 2017 are often on the low side when compared with the UNDP estimates of the TFR in 2015-20: in 13 out of 17 countries, where the IHME and UNDP estimates of the TFR differed by 0.5 or more, the IHME gave a lower TFR (Map 1). In 23 out of 53 African countries analysed, the IHME range of $\mathrm{Cl}$-95 did not overlap with the UNDP point estimate. The mismatch was most serious and most systematic in Central Africa, where the IHME Cl_95 estimate of the TFR differed from the UNDP TFR in each of the nine countries, of which in eight countries (all except Chad) the IHME data were considerably lower, with the absolute gap in the estimated TFR reaching 1.1-1.2 in Central African Republic, Congo, Gabon, and São Tomé and Príncipe.

Of course, estimating fertility in Africa is much trickier than computing fertility in Germany or Finland. But given the seemingly unreliable IHME estimates even for these two countries, one is left wondering

\footnotetext{
${ }^{4}$ Bosnia and Herzegovina suffers large outmigration and uncertainty in its population data, with the recent (2013) census results being disputed (Recknagel 2016), whereas there are no doubts about the quality of population registers in Finland, where the collection of vital statistics data spans back to the 18th century (Lutz 1987).

${ }^{5}$ While the impressively large team of the IHME researchers working on the retrospective estimates "failed" to properly locate the hotspot of global low fertility, the researchers claimed that the lowest fertility globally is in Cyprus (TFR 1.01, Cl_95 0.87 to 1.17), a claim repeated in many media at the time. However, this estimate is far off from the officially reported TFR in Cyprus at 1.32 in 2017 (data exclude Northern Cyprus; Eurostat 2020).

${ }^{6}$ The list of the team of researchers and collaborators and their affiliations in the 2018 study in Lancet (Murray et al. 2018) covered more than 11 densely printed pages.
} 
whether the IHME team has not systematically underestimated the initial fertility level in Africa in the base year of the projection (see also Alkema 2020). On balance, biased estimates of the base data could affect the projection scenarios in three ways: 1 ) providing an incorrect estimate of fertility level in the base year of the projection, 2) giving a wrong trajectory of initial fertility trends during the first years of the projection, and 3) biasing the computation of the parameters of predictive model of fertility, which may, for instance, give a projection of a faster fertility decline. The second point is illustrated in Figure 2, comparing officially reported TFR in 2000-2018 or 2019 (Finland, Germany, Republic of Korea, Turkey) or annual TFR in 2000-2018 estimated by UNDP (Egypt, Philippines) with the past and projected TFR in 2000-2025 derived by IHME. In these countries, the IHME failed to capture the actual magnitude of fertility decline in Finland, Philippines, and the Republic of Korea, whereas it estimated lower-thanobserved fertility in Egypt, Germany, and Turkey.

Figure 1: Mismatch between officially reported TFR in 2017 and the TFR in 2017 estimated by the IHME (point estimate and $95 \% \mathrm{Cl}$ ). Selected low-fertility countries with high-quality population data (left panel) and selected countries from Asia and South-Eastern Europe (right panel)

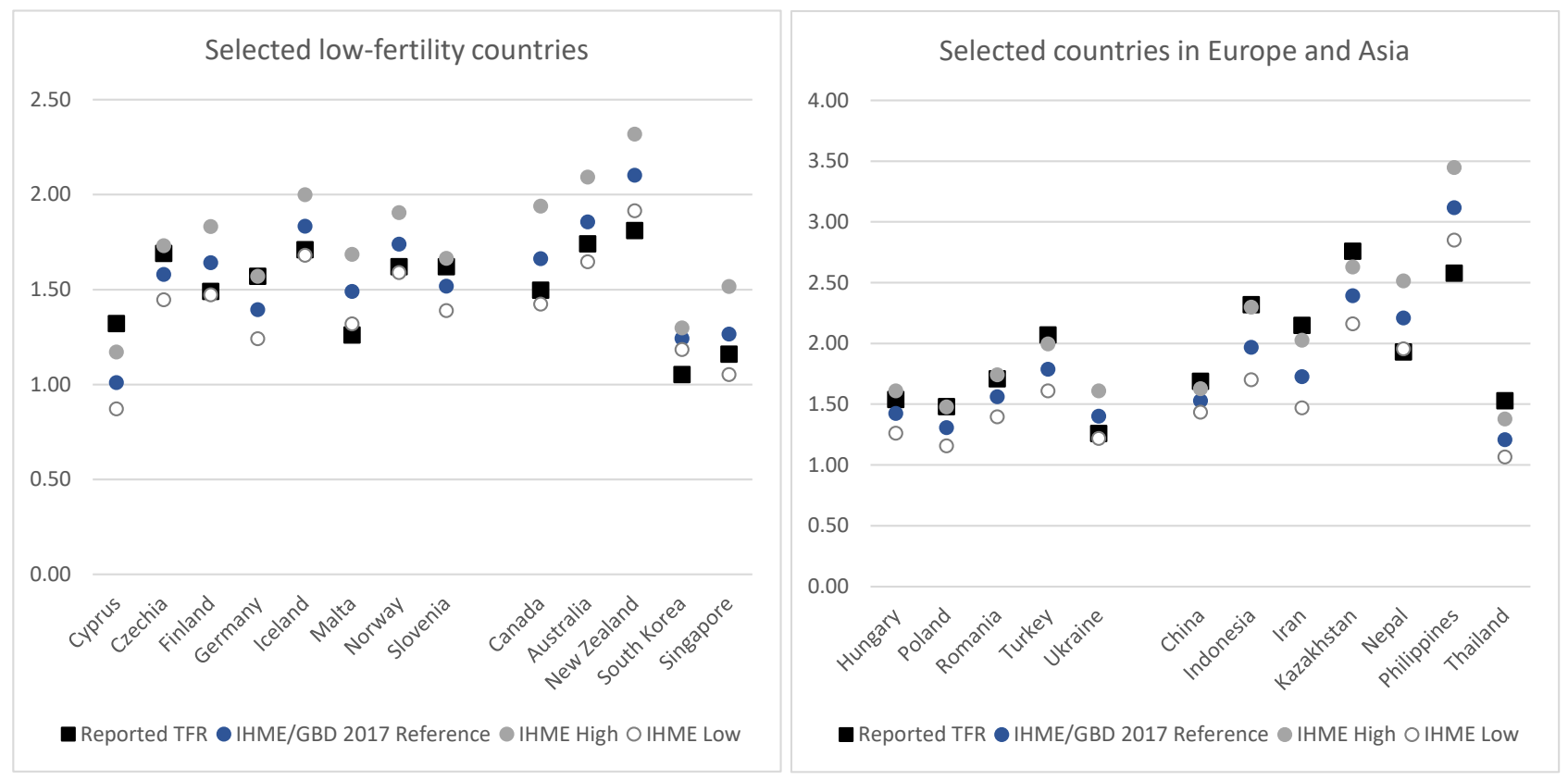


Map 1: Differences in baseline estimates of the period TFR in Africa between the IHME data for 2017 and UNPD (2019) data for 2015-20 (negative values show countries, where IHME estimates are considerably lower than UNPD estimates)

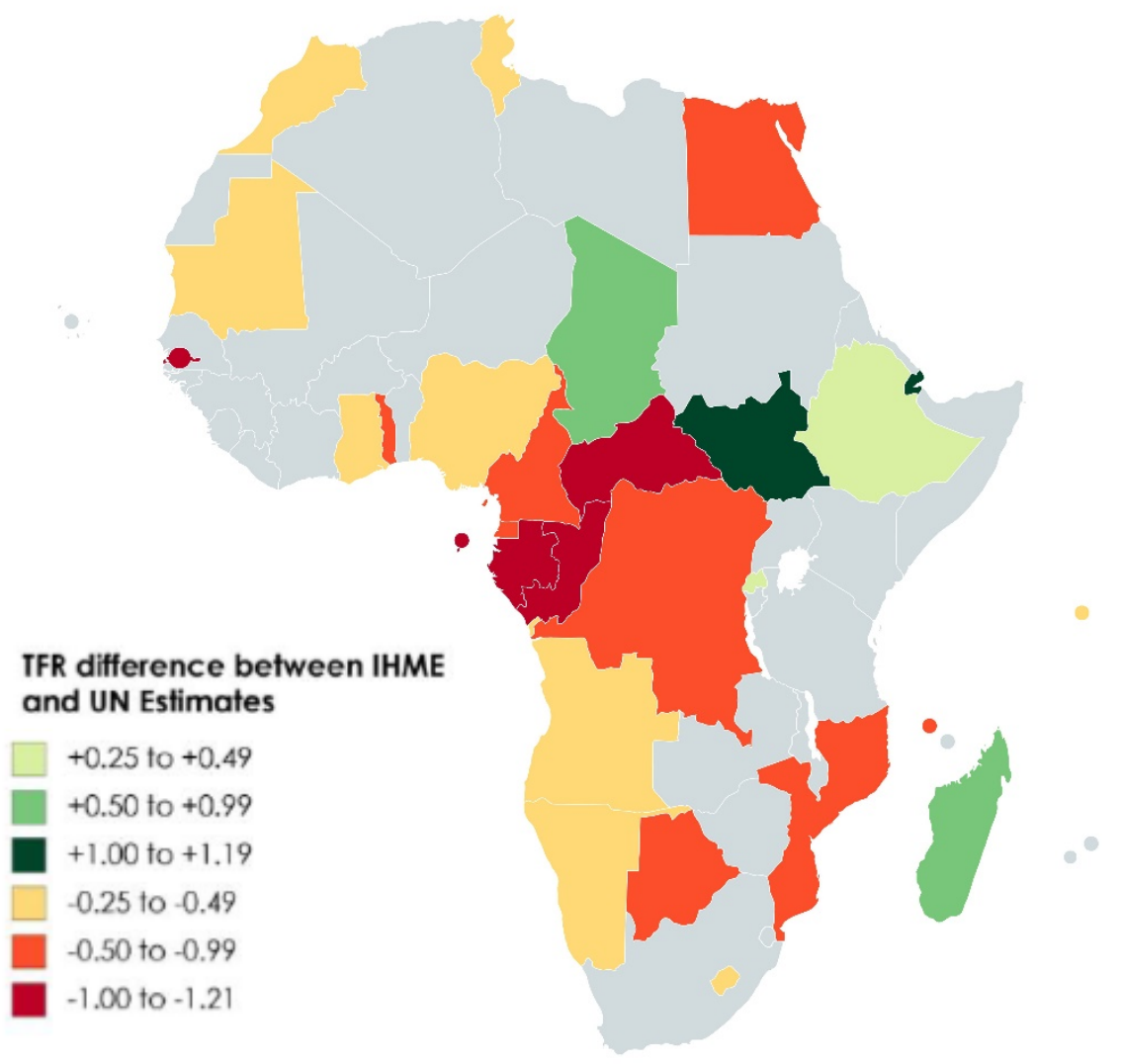


Figure 2: Period TFR reported by official statistical institutions (2000-18) as compared with IHME estimates and projections (2000-2025, point estimate and $95 \% \mathrm{Cl}$ )
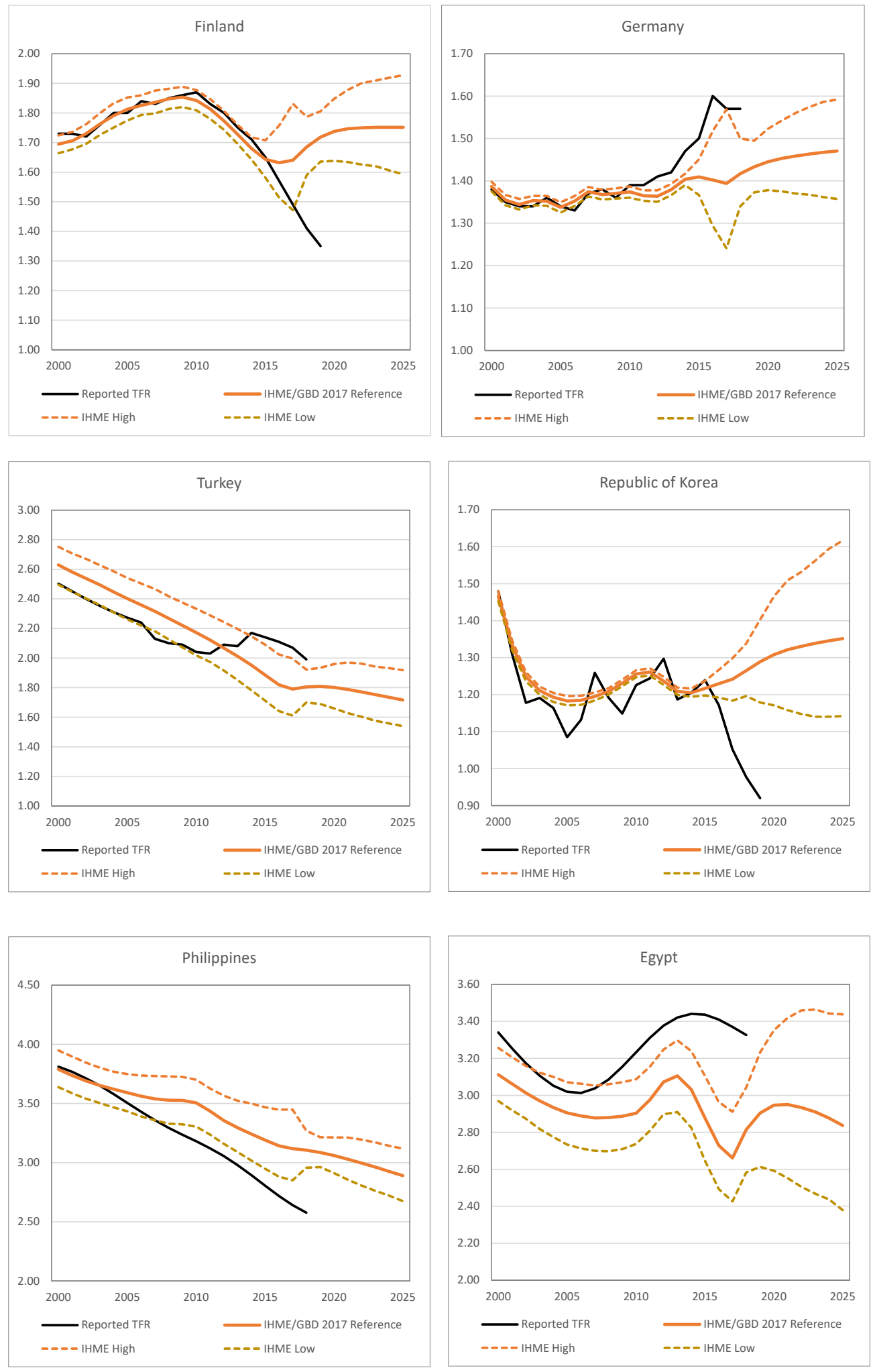


\subsection{Fertility scenarios}

\subsubsection{Demographic perspectives on fertility transition}

Fertility scenarios are key for understanding the differences between the IHME and UNDP projections. Therefore we assess IHME fertility scenarios in finer detail than its mortality and migration scenarios. According to Vollset et al. (2020: 2), the "difference in population forecasts between our reference scenario and the UNPD forecasts is a third due to faster declines in sub-Saharan African fertility and two thirds due to the lower level of TFR expected in populations with fertility lower than the replacement level, especially China and India." The pace, magnitude and persistence of fertility declines are clearly of critical importance for future population trends. Demographers often look at fertility declines from the perspective of 'fertility transition,' a process of long-term fertility decline that proceeds hand in hand with societal modernisation, economic growth, mortality decline (especially child survival), and the spread of education, urbanisation and modern contraception. ${ }^{7}$ Once initiated, the fertility transition is expected to progress until reaching levels at or below population replacement. ${ }^{8}$ Two broader issues frequently debated by population experts are also of key relevance for population projections. First, what drives the fertility transition and how countries differ in its dynamics, including its onset, intensity and duration? Second, what are the trends and determinants of 'post-transitional' fertility in countries that reached low fertility levels? (e.g., Bongaarts 2002; Sobotka 2017).

Perhaps the main insight in this perspective is that fertility dynamics and its drivers differ between the transitional and post-transitional countries. Population research in the last two decades has provided many findings that are highly relevant for discussing the IHME scenarios. At the high-fertility end, among the societies in the early stage of the fertility transition, much research has been devoted to explaining late, slow and stalled fertility transitions, especially in some countries in Sub-Saharan Africa (Bongaarts 2008; Shapiro and Gebreselassie 2008; Bongaarts and Casterline 2013). Countries that experienced late, slow or stalling fertility are often 'stuck' in economic and social conditions conducive for retaining higher fertility, including higher mortality, low education, low economic development, and early marriage pattern (Shapiro and Hinde 2020). Many countries with stalled fertility declines around 2000 had experienced stalls in economic progress and in education provision in the 1980s and 1990s (Kebede, Goujon and Lutz 2019). In addition, there is evidence of a distinct pattern of fertility transition in SubSaharan Africa: for a given level of economic development, education, mortality, and urbanisation, fertility in Africa is higher, contraceptive use is lower, and desired family size higher than in other developing countries (Bongaarts 2017). This 'African effect' is quite large - it is estimated at 1.1 children per woman when considering the TFR and at 1.2 children per woman when considering desired family size (Bongaarts 2017: Table 3). The persistence of high desired family size is also reported by Shapiro and Hinde (2020) for the countries with the highest fertility globally: for instance, in Niger, which has the

\footnotetext{
${ }^{7}$ Often, fertility transition is conceptualised as being part of broader demographic transition, with fertility and mortality declines intertwined (Lee 2003).

${ }^{8}$ Fertility levels needed to keep population stable in the absence of migration and mortality improvements; this level is at 2.07 children per woman in societies with very low mortality rates.
} 
highest TFR globally (at 7.08 in 2017 according to IHME 2020), the ideal family size in 2012 was at a stunning level of 9.2 children per woman (Table 2 in Shapiro and Hinde 2020).

At the low fertility end, past research suggests that the drivers and correlates of fertility trends in posttransitional countries differ from the fertility determinants fueling the fertility transition. Level of education remains an important determinant of fertility, but education gradient in fertility is likely to change as a majority of women obtain tertiary degree, especially in countries which support the combination of work career and family life (Adsera 2017, Jalovaara et al. 2019). Fertility trends are also affected by other factors, including employment conditions and their stability, gender equality and family policies (OECD 2011; OECD 2017). Period fertility rates are often unstable, characterised by frequent ups and downs, and fueled by changing policies, labour market shifts, economic conditions and education trends (Sobotka 2017). Many couples postpone first birth to ever later ages, which in turn depresses period fertility rates (Bongaarts 2002). Low-fertility countries also display a persistent gap between desired family size, which is often at or around two children, and considerably lower levels of actual fertility (Beaujouan and Berghammer 2019), indicating that many women and couples are not able to realise their fertility aspirations.

The demographic perspective on fertility transition is helpful in distinguishing transitional and posttransitional stage of fertility change. It also helps us identifying some of the weaknesses of IHME fertility scenarios. The IHME model of fertility change got two broad aspects right: it relies on modelling completed cohort fertility, which is much more stable than period fertility rates, and it recognises the key role of education in driving fertility declines. Future fertility rates of the cohorts born from 2003 to 2085 are projected as a function of two independent variables-achieved education (measured by mean years of schooling) at age 25 and the share of women with met need for contraception. Because the model projects completed cohort fertility, but the projection scenarios rely on period TFRs, additional level of complexity is added when translating the cohort results into period fertility rates.

\subsubsection{Fertility scenarios for high-fertility countries in Sub-Saharan Africa}

For the 'transitional' countries with higher fertility rates, the two factors used in the IHME fertility modelling-mean years of schooling and met need for contraception-belong to the major drivers of fertility decline identified in the literature. The key issue is how plausible are IHME scenarios for African countries. These scenarios depict a lower starting level of the TFR in Sub-Saharan Africa and its faster decline than the main variant of the UNDP WPP 2019 projection: by 2067 the IHME projects a TFR falling to 2.00 in the Reference scenario compared with the UNDP main variant projecting a TFR of 2.62 in $2065-70$, i.e., by $24 \%$ lower (Figure 3 ). IHME may overstate both the likely pace of fertility decline in the next decades and how low it may get during this century (see also Alkema 2020; Ezeh et al. 2020, O'Sullivan 2020).

We could not evaluate the plausibility of the projection parameters of the mean years of schooling and met need for contraception underlying the IHME fertility scenarios. However, we find several aspects of IHME fertility scenarios questionable for the currently high-fertility countries. One is the pace of 
envisioned fertility change in the countries with the past history of slow or stalling fertility decline. Alkema's (2020) analysis suggests that projected fertility declines in high-fertility countries with low levels of contraceptive use are probably overestimated due to an upward bias in the projections of future increase in contraceptive use and met need for family planning. ${ }^{9}$

Another issue of concern is the seeming asymmetry in alternative fertility scenarios in these countries, with a number of scenarios (Reference Scenario, SDG scenario, Faster Met Need and Education and Fastest Met Need and Education) all envisioning very rapid fertility declines and only one scenario providing a contrasting and possibly exaggerated picture of the 'business as usual' continuation of slow fertility changes. Taking an example of Niger, where IHME estimates that the TFR fell by about $10 \%$ (from 7.82 to 7.08) in almost three decades between 1990 and 2017, all scenarios except one show the TFR plummeting below 2 by 2084, with a rather narrow variation between 1.64 (SDG Scenario) and 1.98 (Reference scenario). By contrast, the only real alternative scenario, 'Slower Met Need and Education' (termed here 'Slower scenario') shows a truly contrasting level of 5.32 in 2084 and is by a factor of 2.7 higher than the next, Reference, Scenario (Figure 4). Considering the past history of slower-thanexpected fertility declines in many parts of Africa, the IHME projection fails to develop a 'middle-of-theroad' scenario of continuing gradual fertility declines that would lay in-between the four scenarios envisioning rapidly falling fertility and the Slower scenario expecting that fertility will remain at a very high level for decades. When it comes to specific trajectories envisioned for individual countries, there are many odd trends and seemingly illogical contrasts, which we illustrate further below. Finally, the IHME work fails to account for the persistently high fertility preferences in parts of Sub-Saharan Africa, mentioned above.

\footnotetext{
${ }^{9}$ In addition, Alkema's (2020) analysis reveals serious shortcomings in IHME validation exercise checking retrospective performance of their fertility projection model. Furthermore, she points out that the fertility projection model which incorporates data on met need for contraception as a key 'predictor' is flawed as it does not reflect changes in the proportion of women who want to avoid or postpone pregnancy. As a result the model employed by IHME "does not even capture a simple causal relation between main family planning indicators and fertility reductions" (p. 5).
} 
Figure 3: Estimates of recent TFR trend (2000-2018) in Sub-Saharan Africa according to IHME and UNDP and projected TFR (2019-2100) according to the Reference scenario of IHME and the Main scenario of UNDP (WPP 2019)

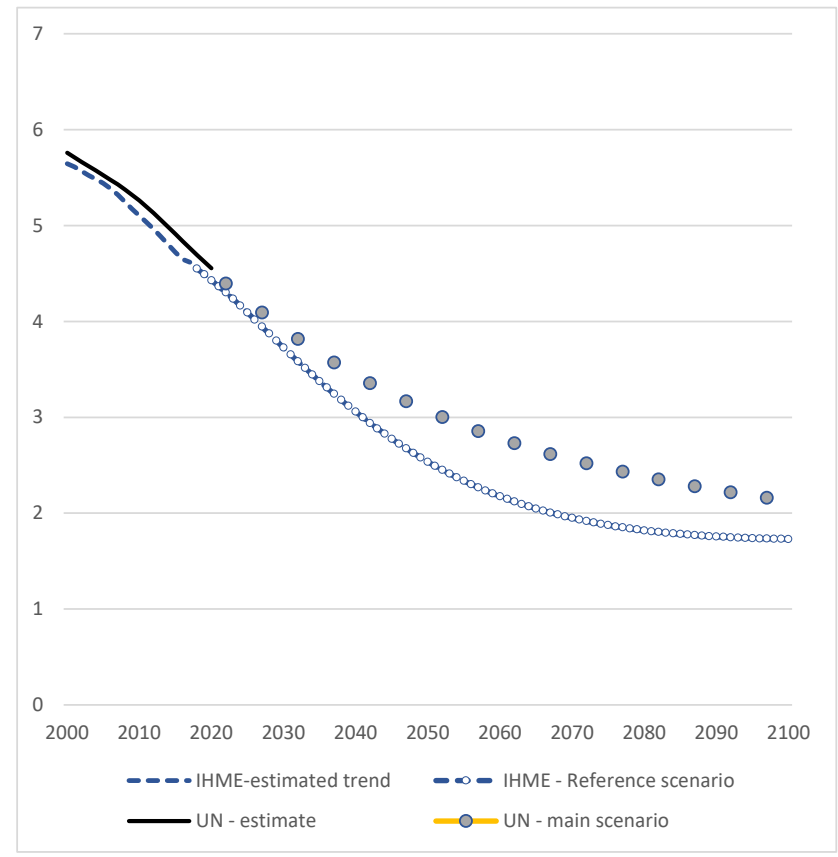

Figure 4: Estimated TFR (2000-2017) and projected fertility scenarios for Niger (2018-2100) according to IHME projections

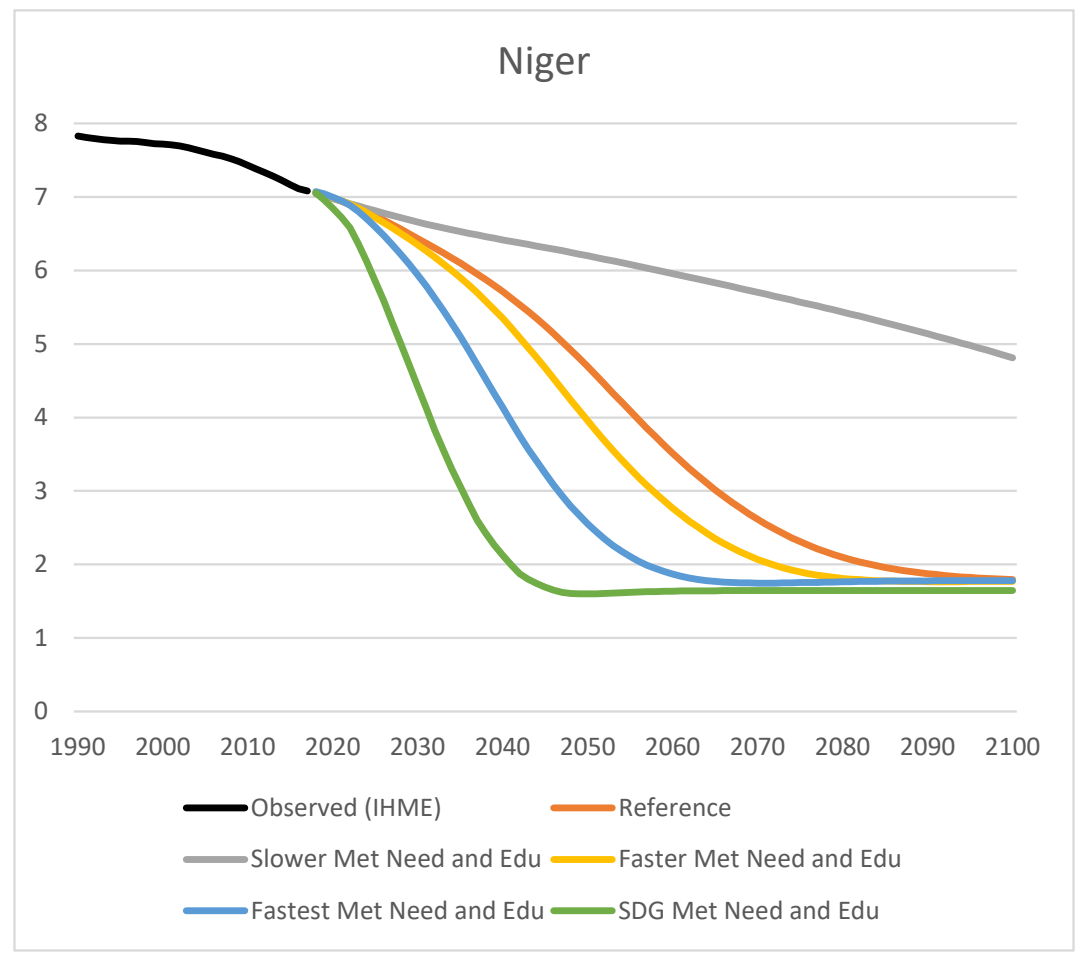




\subsubsection{Fertility scenarios for low fertility (post-transitional) societies}

We also identified many critical issues with IHME fertility scenarios for low-fertility countries. The predictive model of fertility based on mean years of schooling and unmet need fails to capture the experience of post-transitional countries. In low-fertility countries with generally high levels of achieved education the link between education and fertility becomes more nuanced, requiring a careful investigation of the changing education gradient in fertility (Sobotka et al 2017). Of key relevance is the fertility trend among women with university education and whether they will be able to realise their reproductive preferences (Adsera 2017). If there is any correlation between the "mean years of schooling" and fertility rates in low-fertility countries, it turns out positive in both period and cohort perspectives, as illustrated for Europe in Figures $5 \mathrm{a}$ and $5 \mathrm{~b}$. This contrasts with the earlier pattern in 1970, when higher mean years of schooling depicted the expected negative link to the TFR. Similarly, the indicator of unmet need for contraception fails to show a correlation with fertility in Europe (Figure 5c). This indicator is not suitable for modelling low fertility scenarios due to the generally low levels of unmet need for contraception in low-fertility countries, but also due to huge uncertainty in the estimates of unmet in countries that frequently do not collect survey data on the issue. ${ }^{10}$ Most IHME scenarios for the currently low-fertility countries show a continuation of very low fertility for the decades to come, with eventual global spread of very low fertility to more regions.

While UNPD scenarios envision a general recovery of period fertility rates to a higher level once the phase of fertility postponement comes to an end, IHME projections imply a permanent shift to very low fertility rates in many countries from Bangladesh to Bosnia and Herzegovina, often implying completed fertility of 1.1-1.3. While not implausible given the recent continuation of fertility declines across many low-fertility regions (e.g., VID 2020), these scenarios are quite radical considering that currently the lowest-recorded levels of completed fertility globally among women born in the late 1970s are around 1.4 in Italy (1.43) and Spain (1.36) (VID 2020). ${ }^{11}$ The IHME researchers substantiate these expectations of a lasting shift to very low fertility by referring to past population projections: "In the past few years, several groups have questioned the validity of (...) assumptions about post-transition fertility" [p.3 in Vollset et al. 2020]. The references given are to the book Empty Planet: The Shock of Global Population Decline (Bricker and Ibbitson 2019) and a 2011 report by Deutsche Bank (Sanyal 2011). Neither of these texts are written by population scientists, and neither systematically explores the validity of UNDP's or Wittgenstein Centre's fertility assumptions.

\footnotetext{
${ }^{10}$ Global estimates of family planning indicators by the team of UNPD researchers (UNPD 2019b; Kantorová et al. 2020) illustrates well the degree of uncertainty in the estimates of unmet need for modern contraception in lowfertility countries. Due to missing data, the $95 \%$ uncertainty interval often gives a wide range around the point estimate. For instance, among all women of reproductive age in Bulgaria, the estimated (projected) 95\% interval of the share with unmet need for modern contraception in 2017 ranged from $11.9 \%$ to 34.0\% (UNPD 2019b). ${ }^{11}$ Yet lower completed fertility rate, of 1.15 for the women born in 1975 at age 42 is reported in the territory of Hong Kong, which has had extreme low fertility for many decades (Census and Statistics Department 2017).
} 
Somewhat striking is also a relatively broad variation in the projected TFRs in low-fertility high-income countries in different IHME scenarios (Figure 6). Considering generally high level of education and contraceptive use in these countries, we would expect that their alternative trends cannot make such a big difference. Finally, as in the case of higher-fertility countries, individual country trajectories of the future TFR often show seemingly contrasting trends and cross-overs that may appear implausible and difficult to substantiate (Figure 9 below).

Figure 5a: Correlation between Mean Years of Schooling and period TFR in European countries, 1970 and 2015

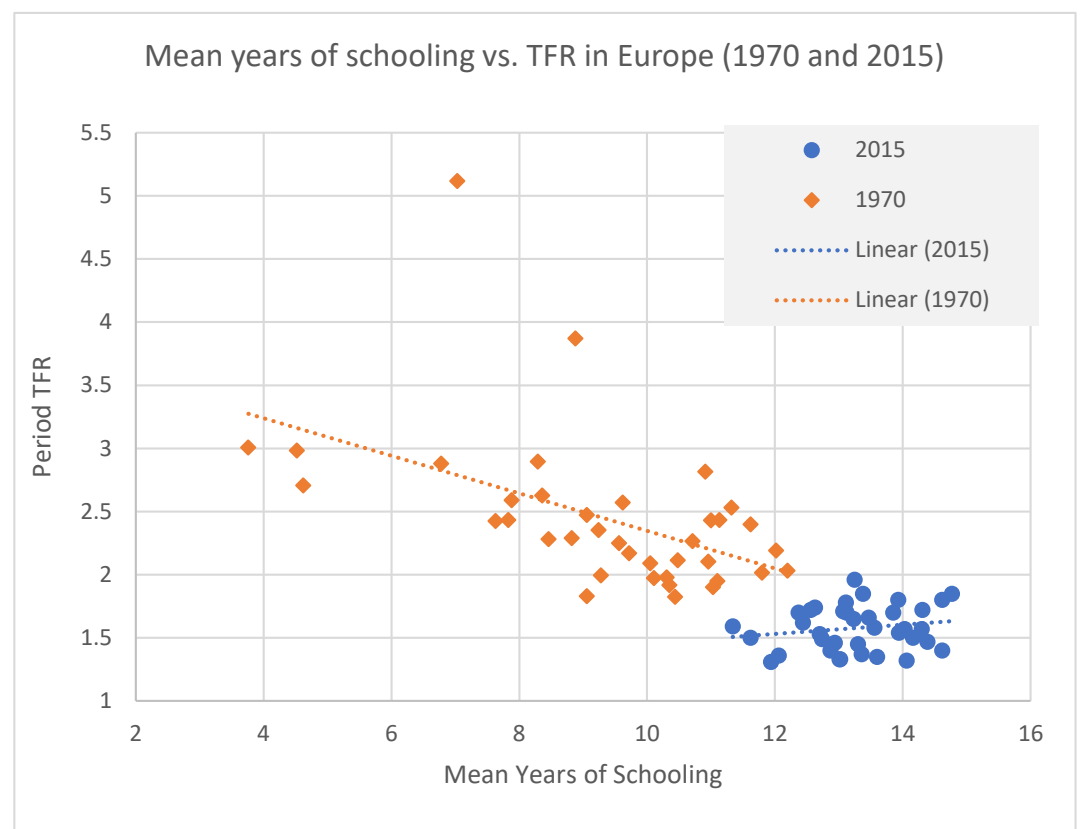

Note: the following countries were excluded due to missing or inconsistent data: Cyprus and Malta in 1970; Bosnia and Herzegovina, Cyprus, Malta and Moldova in 2015.

Data sources: Mean Years of Schooling: Wittgenstein Centre Human Capital Data Explorer (Wittgenstein Centre 2018); Period TFR: Eurostat (2020), Human Fertility Database (2020), Council of Europe (2006) and national statistical offices. 
Figure 5b: Correlation between Mean Years of Schooling in 2005 and completed fertility rates of women born in 1978 in European countries

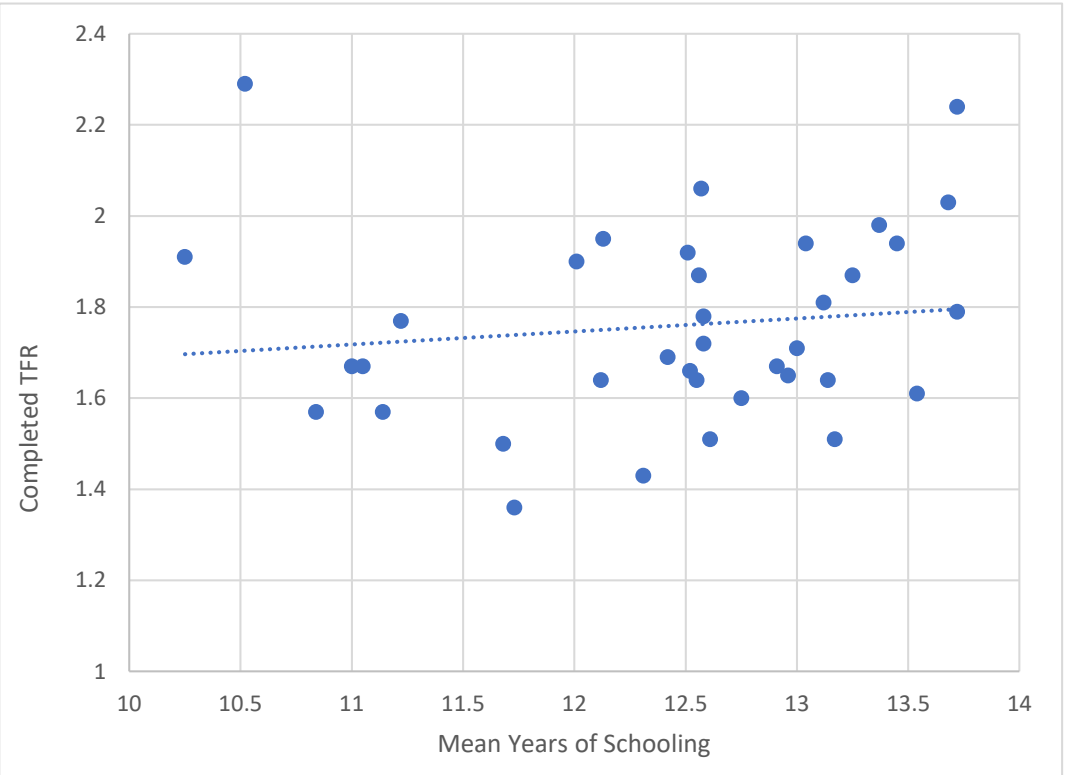

Note: Malta and Moldova were excluded due to missing data on completed fertility rate.

Data sources: Mean Years of Schooling: Wittgenstein Centre Human Capital Data Explorer (Wittgenstein Centre 2018); Completed cohort TFR: European Demographic Data Sheet 2020 (VID 2020).

Figure 5c: Correlation between Unmet Need for Family Planning and period TFR in 2015 in European countries

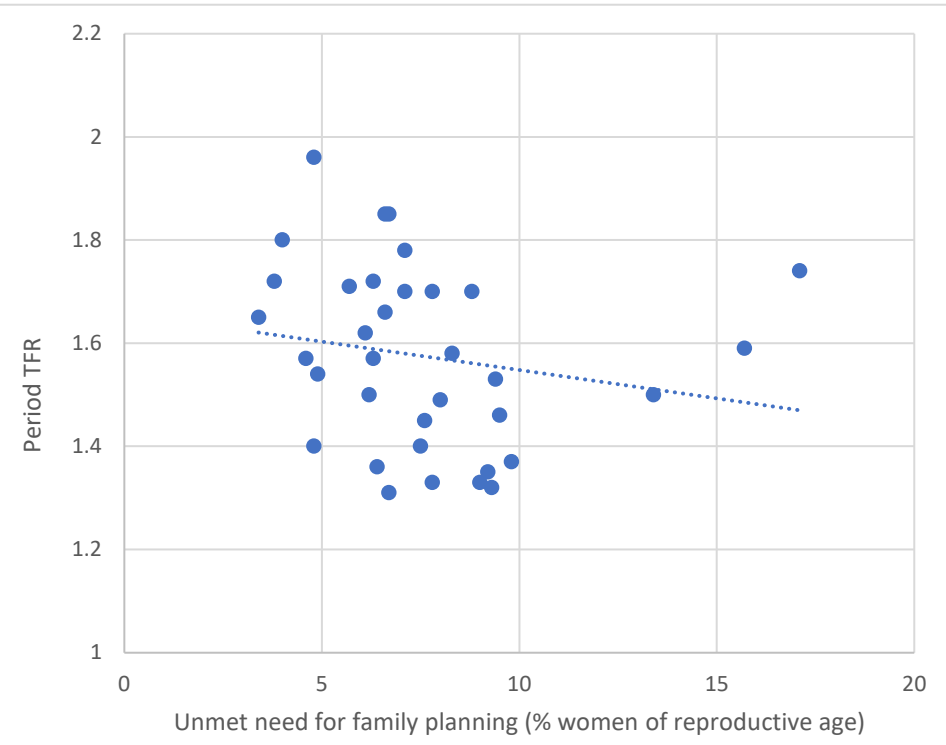

Note: Bosnia and Herzegovina, Cyprus, and Moldova were excluded due to missing or inconsistent data:.

Data sources: Unmet Need for Family Planning: Estimates and Projections of Family Planning Indicators 2019 (UNDP 2019b). Period TFR: Eurostat (2020), Human Fertility Database (2020), and national statistical offices. 
Figure 6: IHME scenarios for the High-Income countries

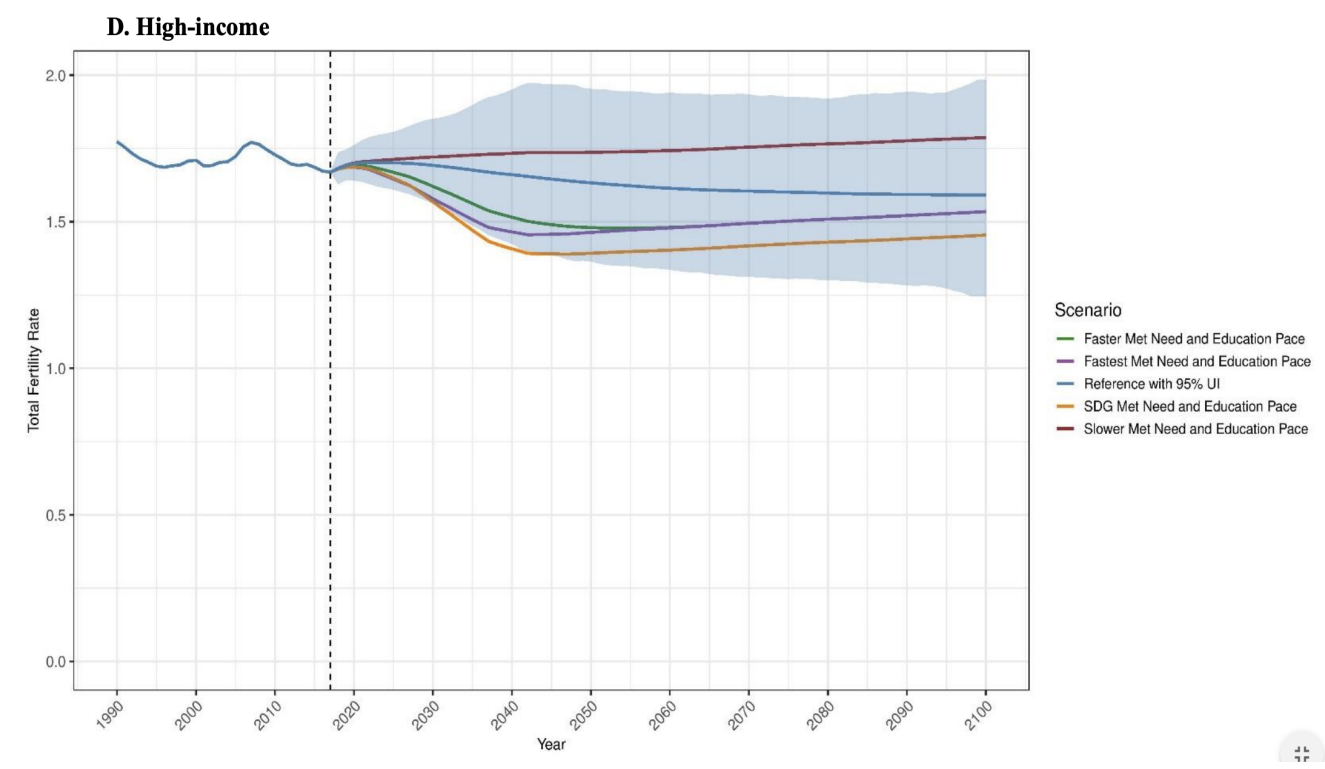

Source: Reproduced from Figure 5 (p. 41) in Appendix 2 to Vollset et al. (2020).

\subsubsection{Main issues with the IHME/GBD fertility scenarios}

After discussing separately the case of transitional countries with higher fertility rates and posttransitional countries with low fertility, we now summarise broader issues with the IHME fertility scenarios, including the seemingly illogical choices concerning basic parameters and limits of the model and the scenarios. Our main general concern is that IHME scenarios, despite their high level of modelling sophistication, often lack internal coherence that would be achieved by an adoption of a unifying overarching perspective, and are strongly affected by a series of arbitrary decisions and parameters. The authors claim the IHME fertility model performed considerably better in predicting the TFR than the UNDP model, but the analysed period was relatively short, spanning ten years from 2008 to 2017 (Section 7 in Supplementary Appendix 2 to Vollset et al. 2020). We find the following issues most problematic about the IHME fertility scenarios:

- Arbitrary lower limits of fertility combined with an absence of upper limits

The regression model predicting future fertility incorporated a lower limit of one birth per woman, a choice which is not substantiated, but prevented the TFR trajectories from falling to absurdly low levels. This resulted in many countries having their future TFR in the late $21^{\text {st }}$ century predicted within a relatively narrow range of 1.0-1.4 in all scenarios except for the 'Slower Met Need and Education Scenario'. The lower limit to fertility also generated asymmetric confidence intervals in the scenarios 
whose point estimate of the TFR is close to this lower limit. ${ }^{12}$ By contrast, the IHME fertility scenarios do not apply any upper limit, resulting in a number of countries expected to retain above-replacement TFRs at 2.1 or higher. The biggest outlier is Samoa, where the Reference scenario predicts a TFR of 4.47 in 2100 (Cl_95 ranging from 2.26 to 7.32). Figure 7 compares the projected TFR trajectory in Burkina Faso (estimated TFR of 5.4 in 2017) and Samoa (estimated TFR of 4.7 in 2017). According to the Reference scenario, the TFR trajectories in these two countries have crossed over in 2019-2020, with Burkina Faso unstoppably heading to a low fertility at 1.4 by the end of the century, while Samoa will retain very high TFR above 4.0 throughout the century (even Cl_95 in these two countries do not overlap since 2060). Such implausible trajectories could have been avoided if the IHME projections incorporated demographic insights on fertility transition.

Figure 7: Observed (IHME estimates for 2000-2017 and UNDP estimate for 2000-2018 for Samoa) and projected (2018-2100) period TFR in Burkina Faso and Samoa, Reference scenario and 95\% confidence interval

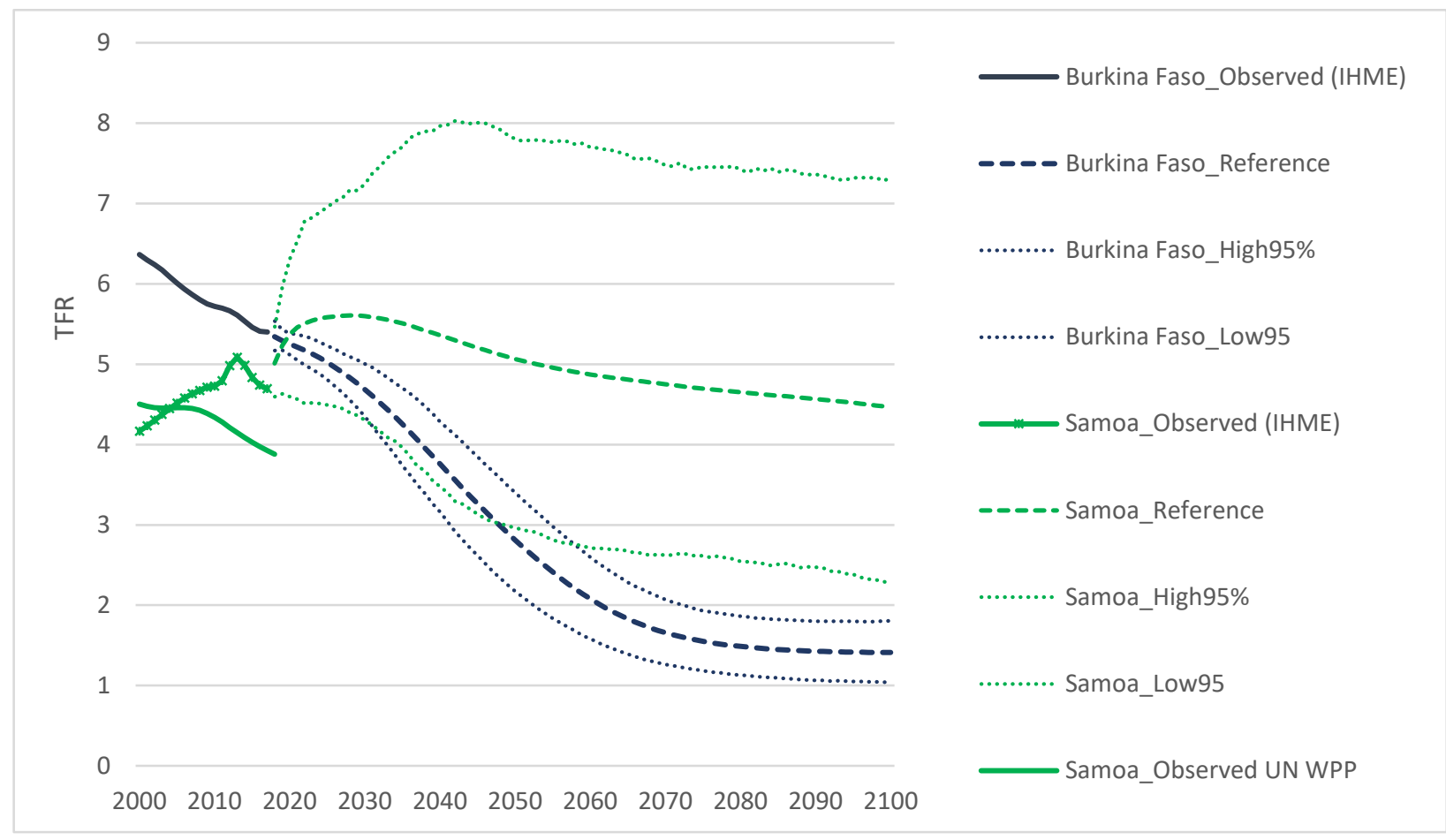

- Missing analytical framework for post-transitional fertility

As we illustrate above, the IHME fertility models, based on mean years of education at age 25 and met need for contraception, does not fit the fertility experience in low-fertility countries that have completed their fertility transition. The questionable assumptions behind the scenarios of low fertility are illustrated in the 'SDG scenario', which shows a further acceleration of fertility decline in the next

\footnotetext{
${ }^{12}$ Often, the confidence interval is therefore expanded above the point estimate and compressed below it, when the point estimate is close to 1 birth per woman. For instance, the SDG pace scenario for Japan envisions a TFR of 1.20 in 2100, with a Cl_95 ranging from 0.95 to 1.85 .
} 
decades as compared with the other scenarios (Figure 6 above). Considering unrealised desire for more children among many couples (Beaujouan and Berghammer 2019) and the trend to higher gender equality and more generous family policies, a more deeply thought-through scenarios broadly compatible with SDGs could instead imply a modest fertility recovery due to higher levels of gender equality and more extensive government support for families.

\section{- What sustains fertility? The expected future hotspots of higher fertility}

One of the consequences of the applied fertility model is an absence of longer-term convergence to subreplacement fertility across countries. Moreover, the expected map of higher fertility in 2100 differs from the map of higher fertility today, which shows a strong concentration of higher fertility in SubSaharan Africa. Among the larger countries (with population above 1 million) expected to retain a TFR at or above 1.85 throughout the $21^{\text {st }}$ century, only four are in Sub-Saharan Africa-Chad, Somalia, South Sudan, and Zimbabwe. Other countries with higher projected fertility are in North Africa and Middle East (Algeria, Egypt, Israel) and many are concentrated in Central Asia (Map 2). However, the limited and inconsistent links between high fertility today and the higher global fertility projected for the year 2100 and the frequent divergence in fertility trends within countries belonging to the same region or country groupings make the projection scenarios for individual countries look implausible. In addition, most countries that are expected to retain above-replacement fertility throughout the 21 century in the Reference scenario have experienced TFR upturn, stabilisation or irregular development in the last two decades. This suggests that relatively short-term fluctuations in fertility during the last two decades have strongly affected projected future TFR trajectories in the next 80 years.

Map 2: Projected future "hotspots" of higher fertility: countries where the Reference scenario projects a TFR at or above 1.85 in 2100

口 I+K ot or cobove 1.85

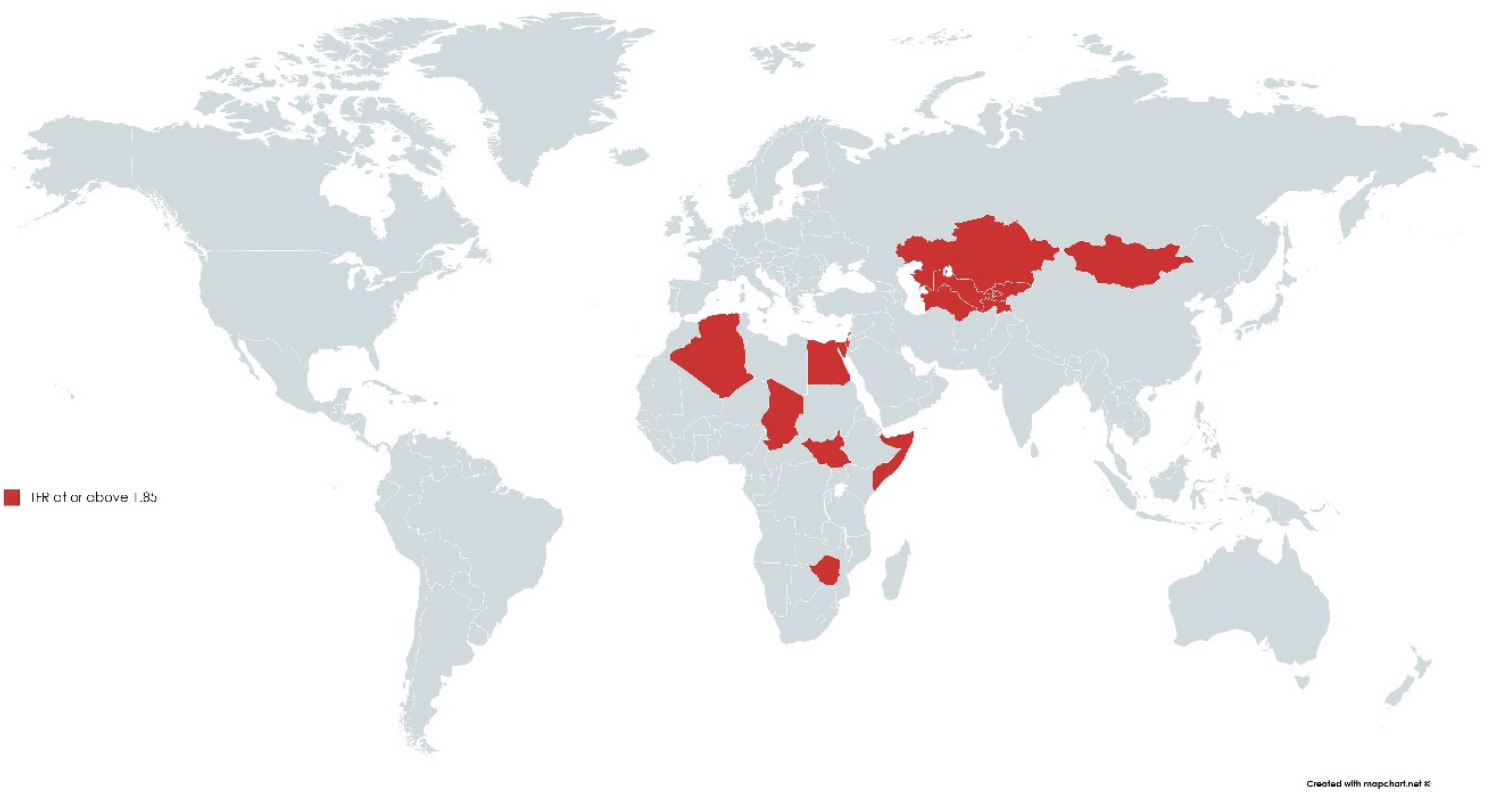


- Wide and inconsistent cross-country variation in projected confidence intervals

The projected fertility trajectories depict wide variation in uncertainty intervals across countries, including countries within broader regions. This variation concerns especially the upper limits of $95 \% \mathrm{Cl}$, where the differences between countries with similar point estimate of TFR can be absurdly high. We illustrate this for selected countries in Figure 8. In the Reference scenario, countries as diverse as China, Eritrea, Kuwait, India, and Mauritania will reach similar levels of projected TFR in 2100, ranging from 1.29 to 1.47. They also share similar projected levels of Low_95 range, from 0.88 in China to 1.12 in Eritrea. However, the upper limit of $95 \% \mathrm{Cl}$ ranges from 1.44 in Eritrea to 2.55 in China and to 3.15 in Kuwait. When compared with the current TFR levels, these upper limits show absurd inconsistencies in IHME fertility scenarios: In Eritrea, which currently has a TFR around 4, the projection suggests it is almost impossible it would retain a TFR above 1.5 by the end of the century. In contrast, in China, with a TFR at 1.4-1.6 in the last few decades, the Reference scenario reckons it is well possible its TFR will rise above 2 in the course of the century. We found similar inconsistencies in the scenarios for Sub-Saharan Africa (see below).

Figure 8: Observed TFR in 2017 (IHME estimate) and projected point estimate and 95\% confidence interval in the TFR in 2100 according to the IHME Reference scenario

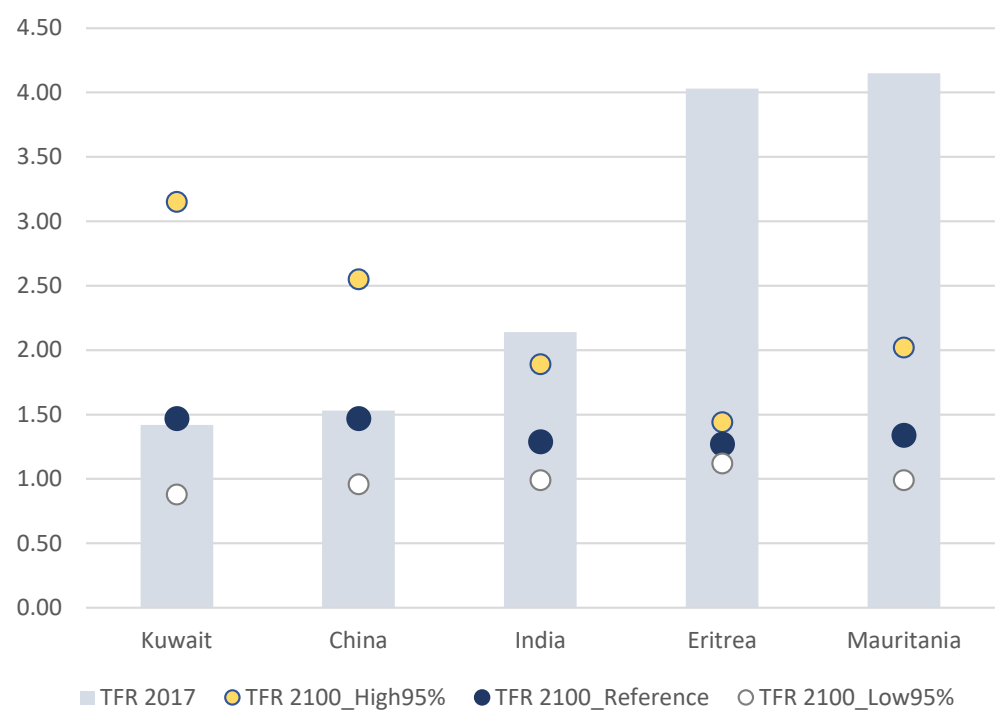

- Wide fertility variation within regions and crossovers in projected fertility trajectories As we illustrate in Figure 9, projected fertility trends in countries belonging to wider geographical regions often depict contrasting and inconsistent trajectories with expected cross-overs in the course of the century. Some countries with relatively lower initial fertility, such as Malaysia in South-Eastern Asia (TFR at 2.1 in 2017), or Egypt and Israel in the Middle East and North Africa (MENA) region are projected to experience only modest fertility declines, whereas other countries with initially much higher fertility (Iraq in the MENA region, Laos and Cambodia in South-Eastern Asia) show sustained fertility falls to much lower levels. Furthermore, there is no consistent link between initial fertility level and the expected fertility decline within broader regions-Algeria and Egypt have similar initial TFR around 2017 
(about 2.8 according to the IHME), but depict different trajectories and levels of fertility decline in the next decades.

Figure 9: Observed TFR in 2000-2017 (IHME estimate) and projected TFR in 2018-2100 according to the IHME Reference scenario: selected countries within broader regions
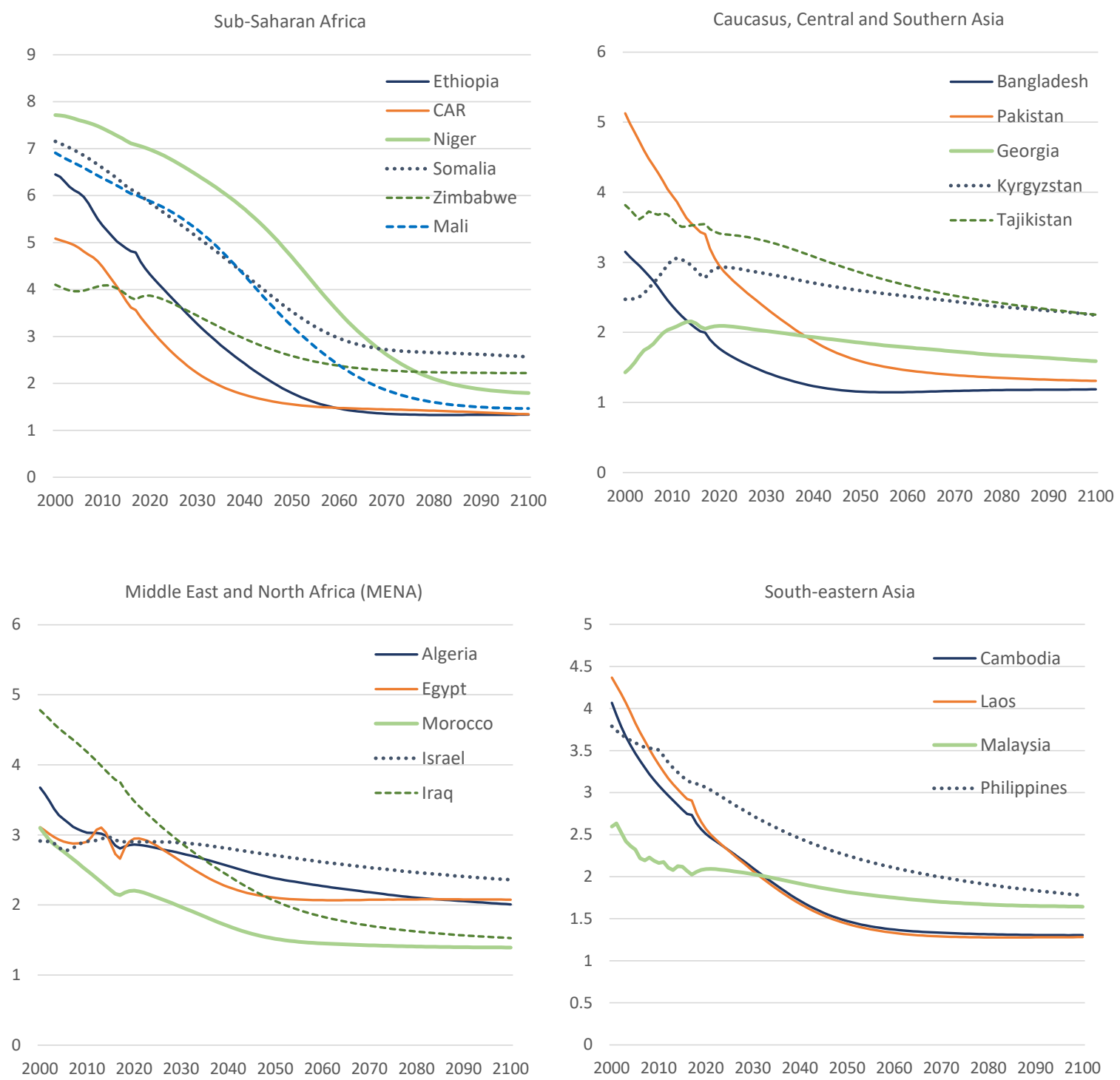

- Fertility in Sub-Saharan Africa: inconsistencies in projected trends and confidence intervals All these issues and inconsistencies are clearly evidenced in Sub-Saharan Africa. Within broader geographical regions, countries with limited fertility declines, which are expected to retain abovereplacement fertility rate throughout the century, such as Zimbabwe, border countries expected to experience much sharper fertility downturns to very low levels, such as Mozambique. Countries with expected low levels of upper limit of TFR uncertainty range, such as Ethiopia (projected Upper Cl_95 at 
1.63 in 2100) share borders with countries that have projected upper limits almost twice as high (Somalia and South Sudan at 2.8-2.9) (Figure 10). The upper limits are not related much to the initial estimate of the TFR in the base year: Mali and Somalia share similar estimated TFR in 2017 (around 6 births per woman), but contrast starkly in the upper Cl_95 in 2100 (1.82 in Mali, 2.88 in Somalia). Because of different country trajectories, the Reference scenario envisions many cross-overs in the TFR between countries (Figure 9 above), but also leads to a complete revamping in the rankings of African countries in their fertility level globally. Today, most of the countries in Sub-Saharan Africa score high on global TFR rankings, with 18 out of 20 countries with the highest fertility located in the region. By 2100, the Reference scenario suggests countries in Sub-Saharan Africa will be distributed across the range of global fertility rankings, with some curious contrasts with today's rankings. For instance, Mozambique, which currently ranks at 31 $1^{\text {st }}$ place in TFR globally (TFR of 4.16 in 2017), would fall to a rank 183 in 2100 (TFR at 1.26). In 2100 African continent is predicted to have both countries with very low TFR below 1.4 and those with a high TFR above 2, with many hotspots of very low fertility projected in Western and Central Africa (Map 3). The underlying logic behind these trends is elusive - they might be possibly explained by the projected scenarios of future education and met need for contraception on the continent, but this is not elaborated in the study by Vollset et al. (2020).

Figure 10: Observed TFR in 2017 and projected TFR in 2100 in selected countries of Sub-Saharan Africa according to IHME Reference scenario (point estimate and Upper 95\% confidence interval); countries ranked by the TFR in 2017

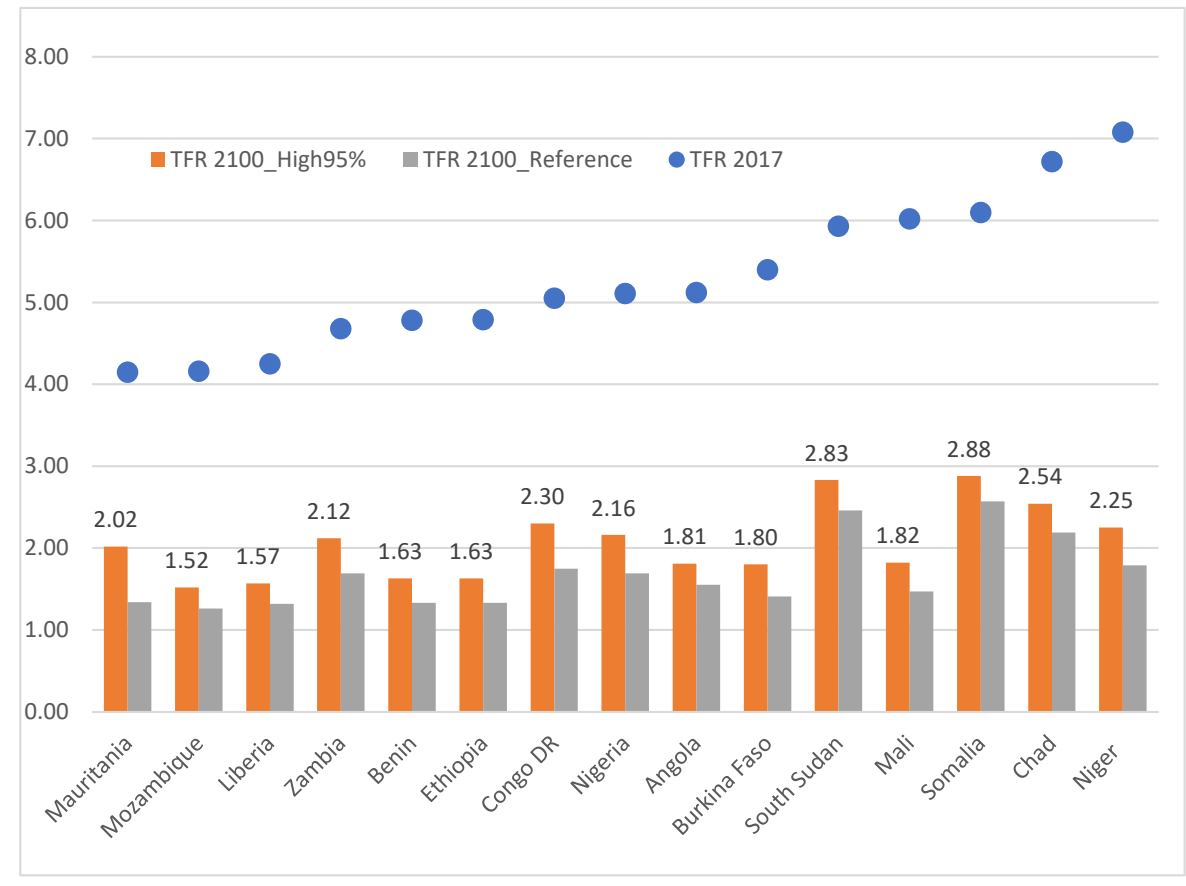


Map 3: Projected TFR in 2100 in selected African countries according to IHME Reference scenario: countries with low (TFR below 1.5) and relatively high (TFR at or above 2.1) fertility

TFR at or above 2.0

TFR at 1.40 to 1.49

TFR at 1.30 to 1.39

TFR at 1.20 to 1.29

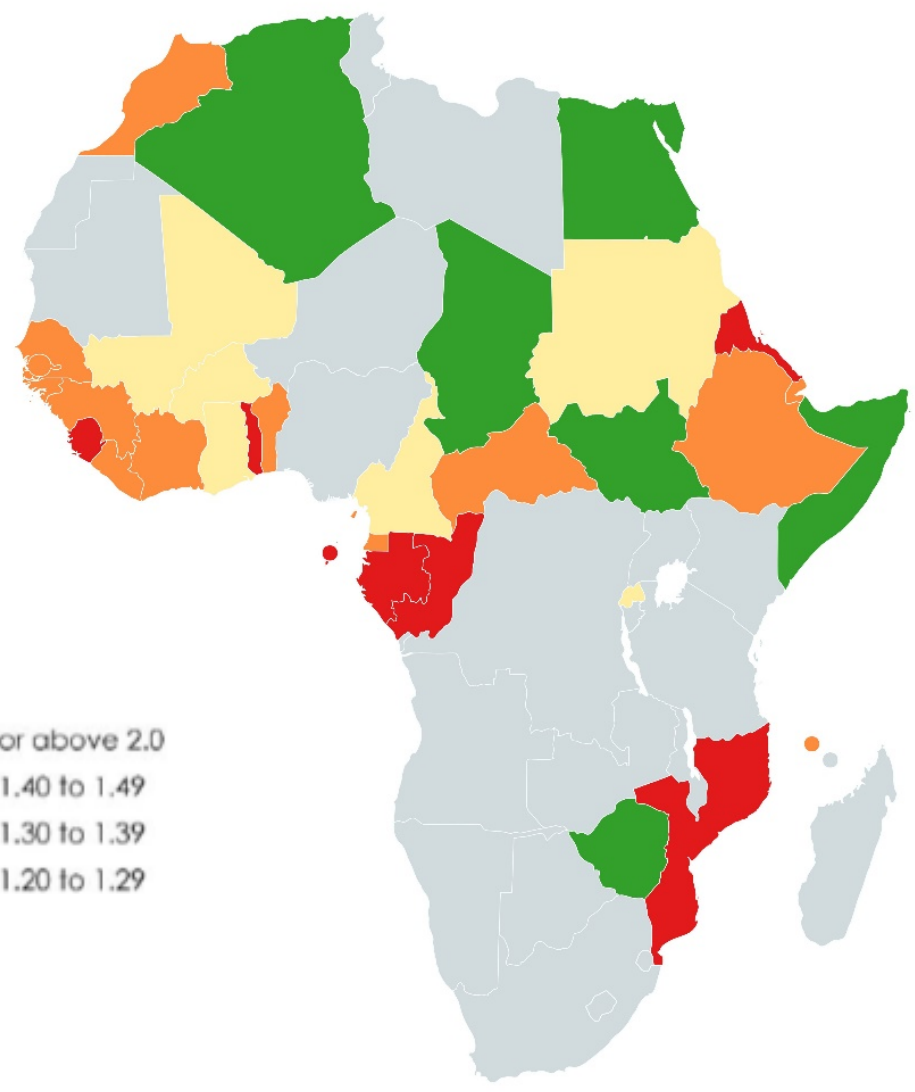

- Fertility in China: almost identical scenarios

The actual fertility levels and trends in China are frequently disputed, with different surveys, censuses and official vital statistics yielding a broad range of TFR estimates spanning from about 1.1 to 1.8 (Morgan et al 2009; He et al. 2019; Guo et al. 2018). It is therefore surprising that the initial TFR for 2017 estimated by IHME has narrow uncertainty range that does not capture this variation (Cl_95 from 1.43 to 1.63). What is further unexpected is an absence of variation in different fertility scenarios for China. For instance, the projected TFRs for 2050 in the five scenarios lie within a very narrow range from 1.39 in the SDG scenario to 1.48 in the 'Slower scenario'. This contrasts with a much wider range of scenarios envisioned for the group of High-income countries (with generally high levels of education and met need for contraception, similar to China; Figure 6 above). Given that China has a huge weight on global population trends and considering the country's history of restrictive family policies that may affect fertility trends, we are convinced that uncertainties about current fertility data in China and the likely future trends should have been reflected in a broader initial uncertainty range and more diverse scenarios in its future TFR trajectories. 
Figure 11: Estimated (1990-2017) and projected (2018-2100) period TFR in China based on IHME data and scenarios

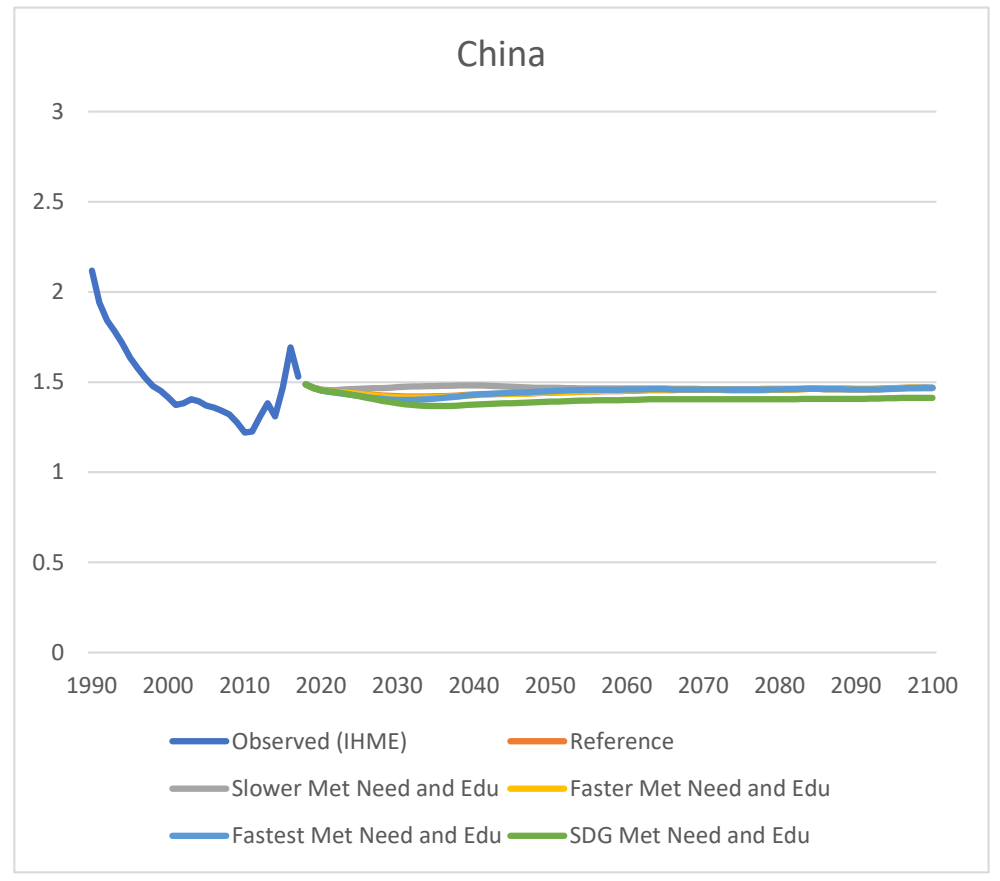

- Implausible "freezing" of distorted sex ratios at birth

Some countries in Eastern, South-eastern and Southern Asia, Southern Caucasus region and Southeastern Europe have recorded distorted sex ratios at birth (SRB) due to sex-selective abortion. Skewed SRBs are linked to entrenched gender discrimination leading to son preference among many couples (Guilmoto and Tove 2015). SRB imbalances have strong implications for population trends. They result in tens of millions of 'missing; girls and women since 1970 (Bongaarts and Guilmoto 2015), but they also imply that at any given level of fertility rates countries with distorted SRBs will have a lower rate of population replacement, as the missing girls will eventually translate into missing mothers and fewer births in the future (Chao et al. 2019; Gietel-Basten and Scherbov 2020). The IHME projection employs a simplistic assumption that the estimated values of sex ratios at birth in 2017 are kept constant through 2100 (p. 3 in Vollset et al. 2020). This implies a continuation of reduced population replacement for the decades to come in countries with currently distorted SRBs such as China, India or Vietnam. However, this assumption is implausible as it ignores three key facts regarding SRB trends and policies. First, SRBs can change in response to government action trying to limit sex selection of fetuses (with the early example of successful policy action in Korea in the 1990s (Chung and Das Gupta 2007)). Second, many governments seek to reduce SRB imbalances and enact legislation combating prenatal sex selection. Third, the skewed SRBs are well past their peaks and have been declining in most countries where gender imbalances among newborns had been reported in the past (Chao et al. 2019). Therefore, IHME scenarios underestimate future population replacement in countries with distorted SRBs and therefore underestimate future numbers of live births and females in their populations. 


\subsection{Mortality scenarios}

In many respects IHME mortality scenarios contrast in their construction and projected dynamics with the fertility scenarios discussed above. The first difference lies in the vast amount of components incorporated in the all-cause mortality model, which is aggregated from cause-specific mortality forecasts by sex and age for 274 causes of death and cause groups (Section 6 in Supplementary Appendix 1 to Vollset et al. 2020). The underlying mortality in these cause-specific models is modelled as a function of Socio-Demographic Index (SDI, composed of Total Fertility Rate, lagged income per capita, and mean years of schooling among population aged 15+) and additional covariates where appropriate. The second difference lies in relatively slow pace of life expectancy changes, with gradual improvements in mortality decelerating over time. ${ }^{13}$ This produces a very conservative trajectory of life expectancy changes, where life expectancy eventually stops improving and stabilises in the lowest mortality countries towards the end of the century, while the higher-mortality countries gradually continue closing the gap in life expectancy with the low-mortality countries. The third difference lies in small variability in mortality scenarios: life expectancy differences across countries narrow down over time and also the contrasts between different mortality scenarios for individual countries are much smaller than the differences between fertility scenarios.

Here we highlight selected problematic features of IHME mortality scenarios, focussing on the predicted decceleration of mortality improvements in the course of the $21^{\text {st }}$ Century, low variation between different scenarios, and illogicala nd inconsistent trends often projected between countries within broader regions.

\subsubsection{Main issues with the mortality scenarios}

- Decelerating mortality improvements: are life expectancy gains reaching their limits? The complex mortality projection exercise, incorporating 274 causes of death, confirms analytical and computational prowess of IHME team. For the countries with the highest life expectancy todaylHME scenarios predict that its improvements will be slowing down in the text decades, eventually coming to an end. This implies that the long-term, seemingly unstoppable, mortality improvements, regularly bringing about new records of highest-reported life expectancy, would fizzle out in the final decades of the $21^{\text {st }}$ century-quite a strong assumption when considering the evidence on long-term rise in life expectancy over the last two centuries (Oeppen and Vaupel 2002; Vaupel et al. 2020). In the case of longevity among women, most of the countries with highest life expectancy today would see their life expectancy peaking below the threshold of 90 years (Figure 12). This means the best-practice life expectancy among women would increase slowly from the current level at over 87 in Japan and Singapore to slightly over 90 in 2100 (when excluding the odd case of Kuwait, see Figure 17). However, life expectancy improvements are expected to slow down across all groups of countries, including those with higher mortality today (Figure 13). As a result, many countries are expected to see a slower rise in

\footnotetext{
${ }^{13}$ This decelerating trend is driven by applying a slope attenuation adjustment in the linear regression model forecasting all-cause mortality (Section 6.2 in Supplementary Appendix 1).
} 
life expectancy in more than eight decades between 2017 and 2100 than they recorded in less than three decades between 1990 and 2017 (Figure 14). These unambitious scenarios imply that even by 2100 only 32 countries globally would reach life expectancy of 87 or higher among women, which is the levels achieved in Japan today. This level would not be reached, for instance, by woman in the United States, Norway or China. Women in India and men in South Africa are not expected to reach by the end of the century the level of life expectancy recorded in Japan in 1990 (Figure 15).

Figure 12: Estimated (1990-2017) and projected (2018-2100) life expectancy at birth among women in selected low-mortality countries (IHME Reference scenario)

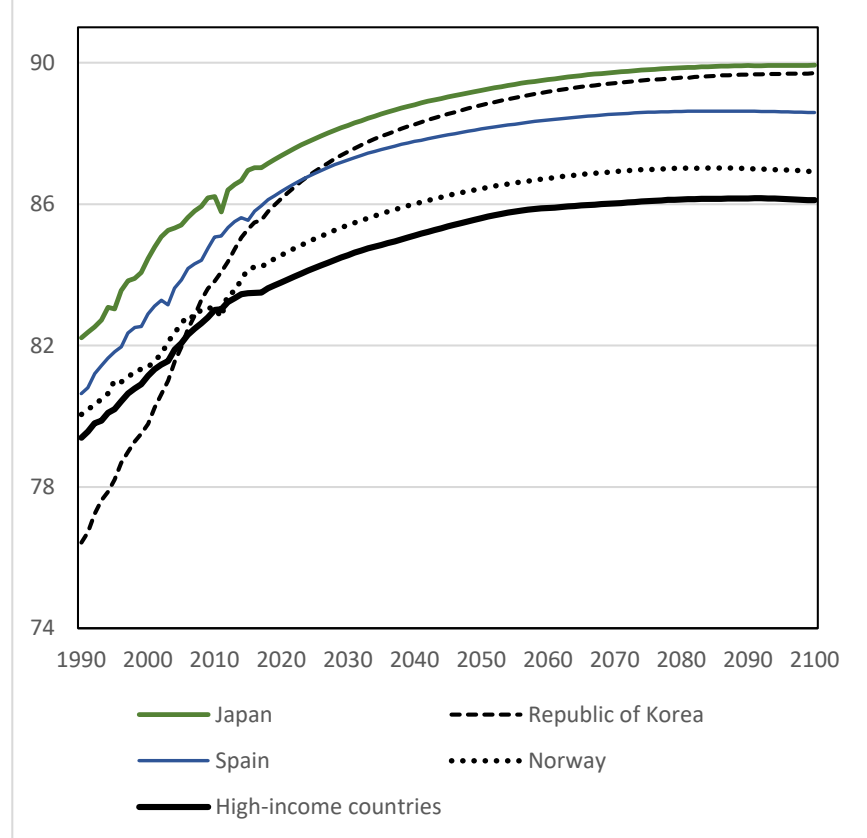


Figure 13: Estimated (1990-2017) and projected (2018-2100) absolute changes in life expectancy at birth among women in selected low-mortality countries per decade (IHME Reference scenario)

Changes in life expectancy of women per decade, observed (1990-2017) and projected (2017-2100)

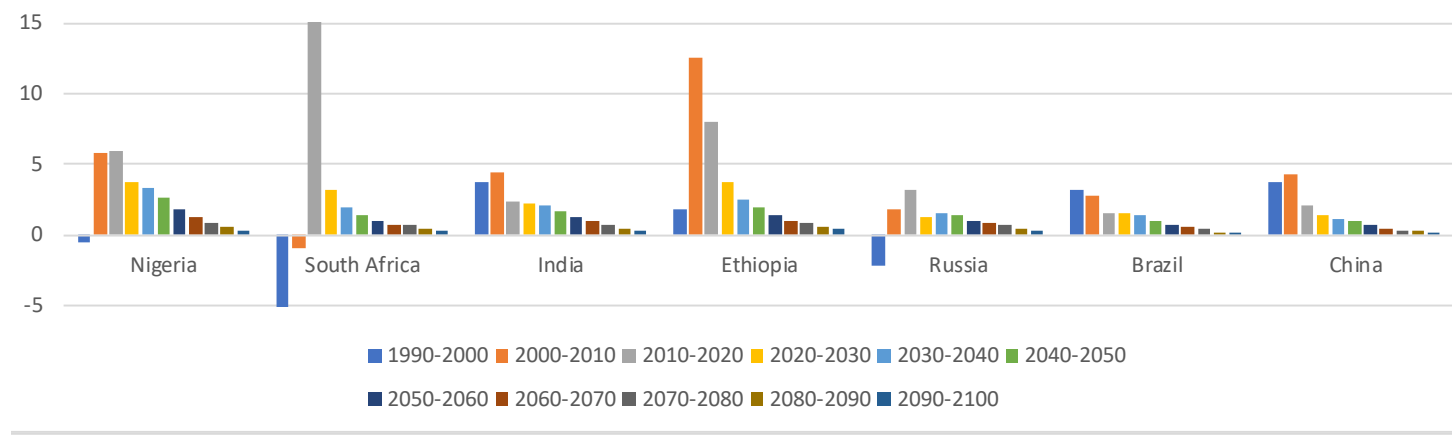

15

10

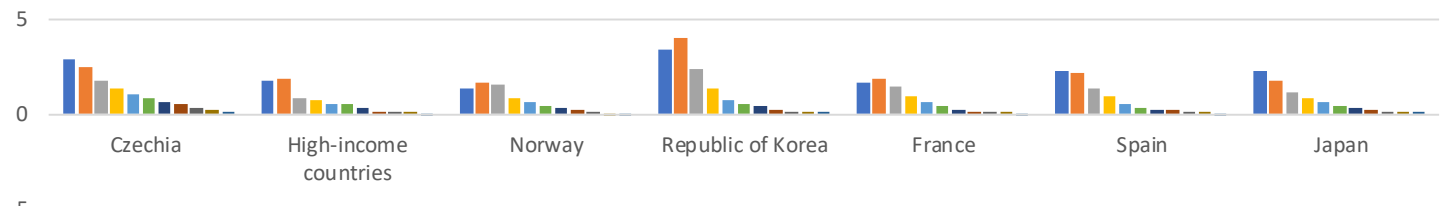
$-5$

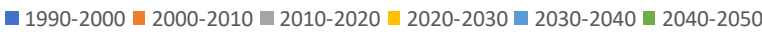

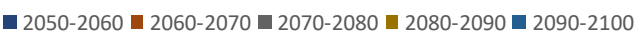

Figure 14: Estimated (1990-2017) and projected (2018-2100) absolute changes in life expectancy at birth among women in selected low-mortality countries (IHME Reference scenario)

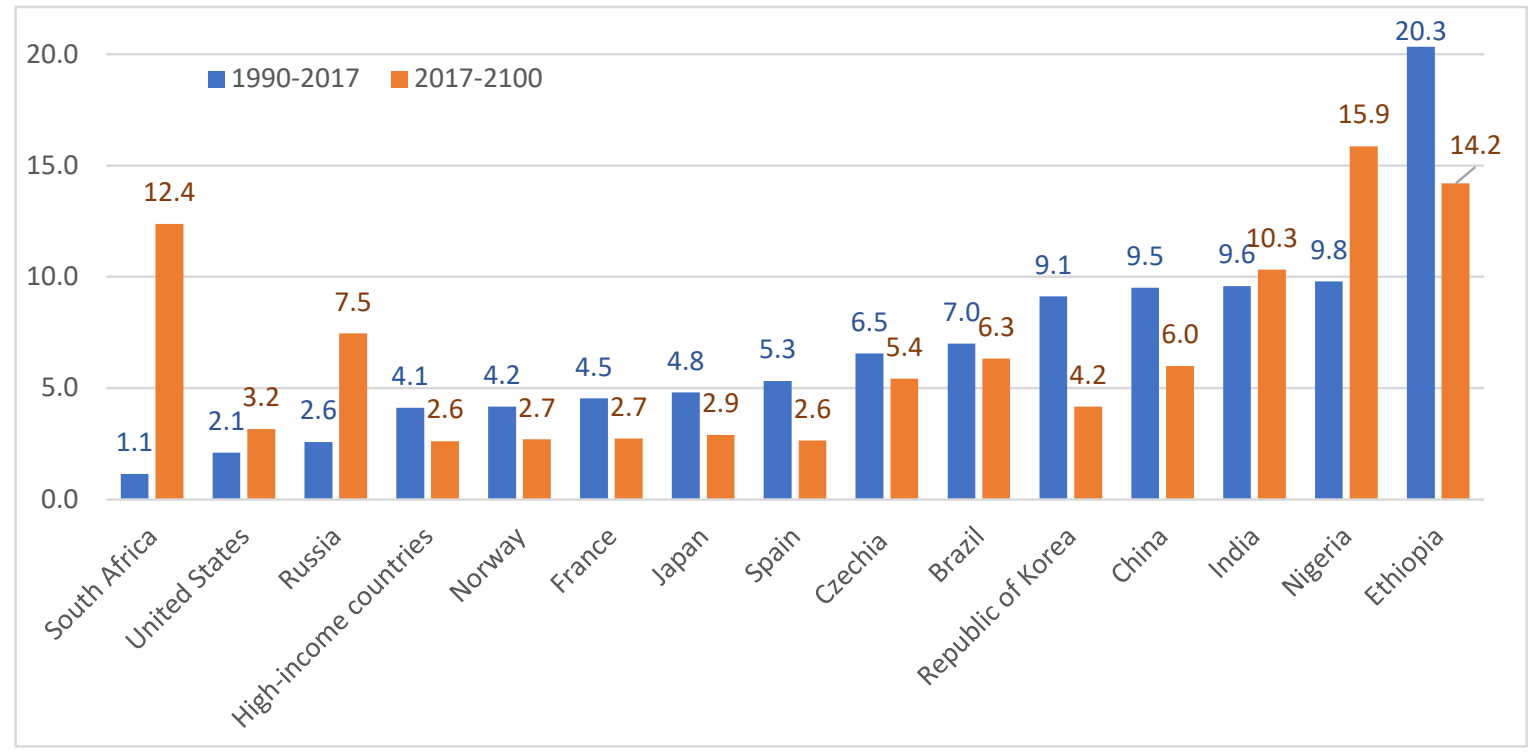


Figure 15: Projected life expectancy at birth among women and men in selected countries in 2100 (IHME Reference scenario) compared with observed (1990 and 2017) and projected (2100) life expectancy in Japan

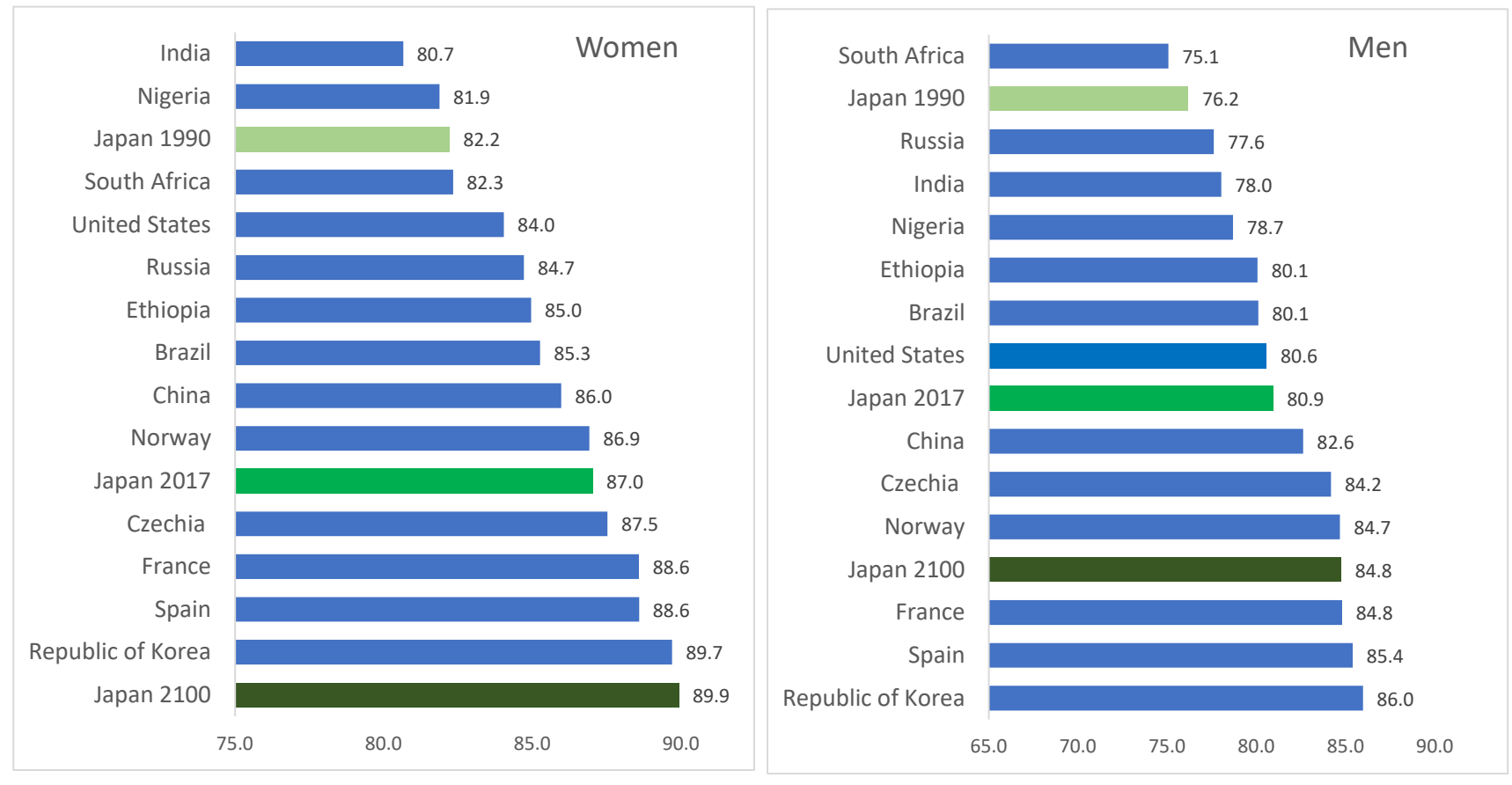

- Low variation in life expectancy scenarios

In contrast to fertility scenarios, where the 'Slower scenario' often differs a lot from the other scenarios, scenarios of life expectancy usually show life expectancy levels in 2017-2100 evolving within a narrow margin. For instance, the five scenarios of life expectancy at birth among men in India in 2100 vary by less than a year, spanning from 77.37 to 78.23 years (Figure 16). The limited variation in projected mortality levels indicates that the IHME projection fails to factor in possible effects of continuous substantial improvements in mortality as well as possible future mortality shocks. For countries with medium or low current levels of life expectancy this implies that the IHME team largely ignored the possibility of long-term continuation of life expectancy improvements envisioned by Vaupel et al. (2020). Possible technological and medical breakthroughs leading to long-term expansion in longevity and life expectancy are partly factored in through uncertainty intervals around different scenarios, but not as distinct alternative scenarios for all countries. 
Figure 16: Observed (1990-2017) and projected (2018-2100) life expectancy at birth among men in India according to different IHME scenarios

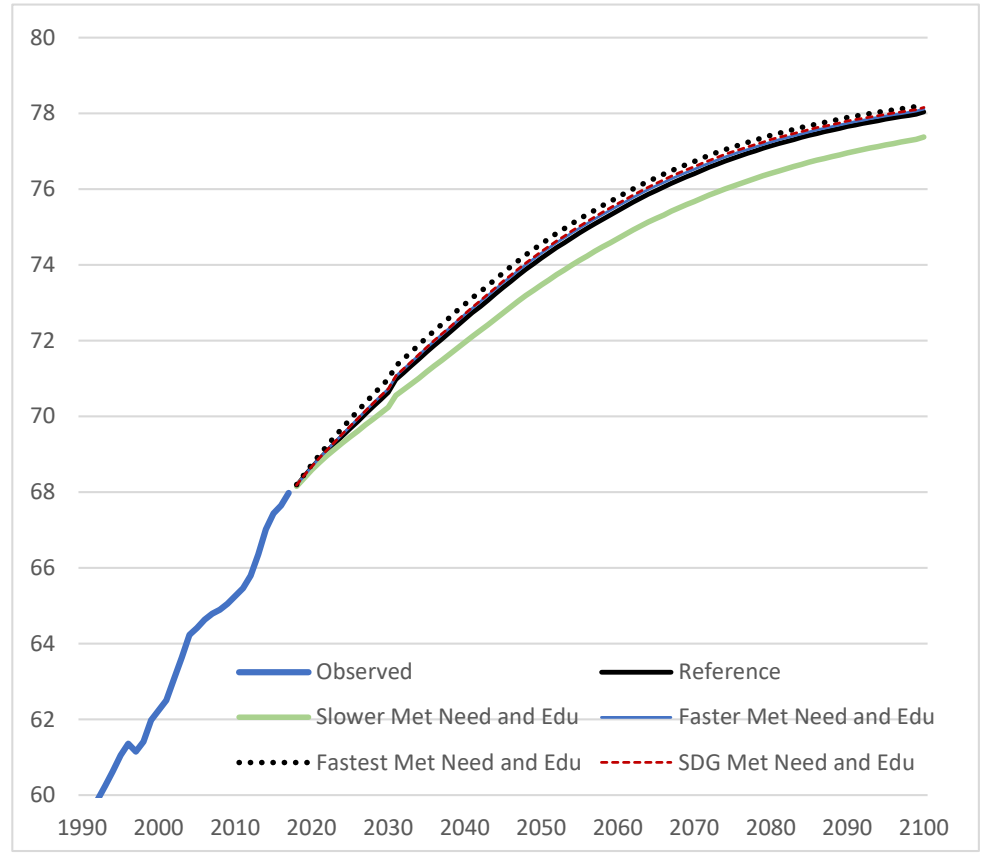

Figure 17: Projected best-ranking countries in life expectancy among women in 2100 according to the IHME Reference scenario, compared with the estimated life expectancy in 2017 according to IHME and UNDP

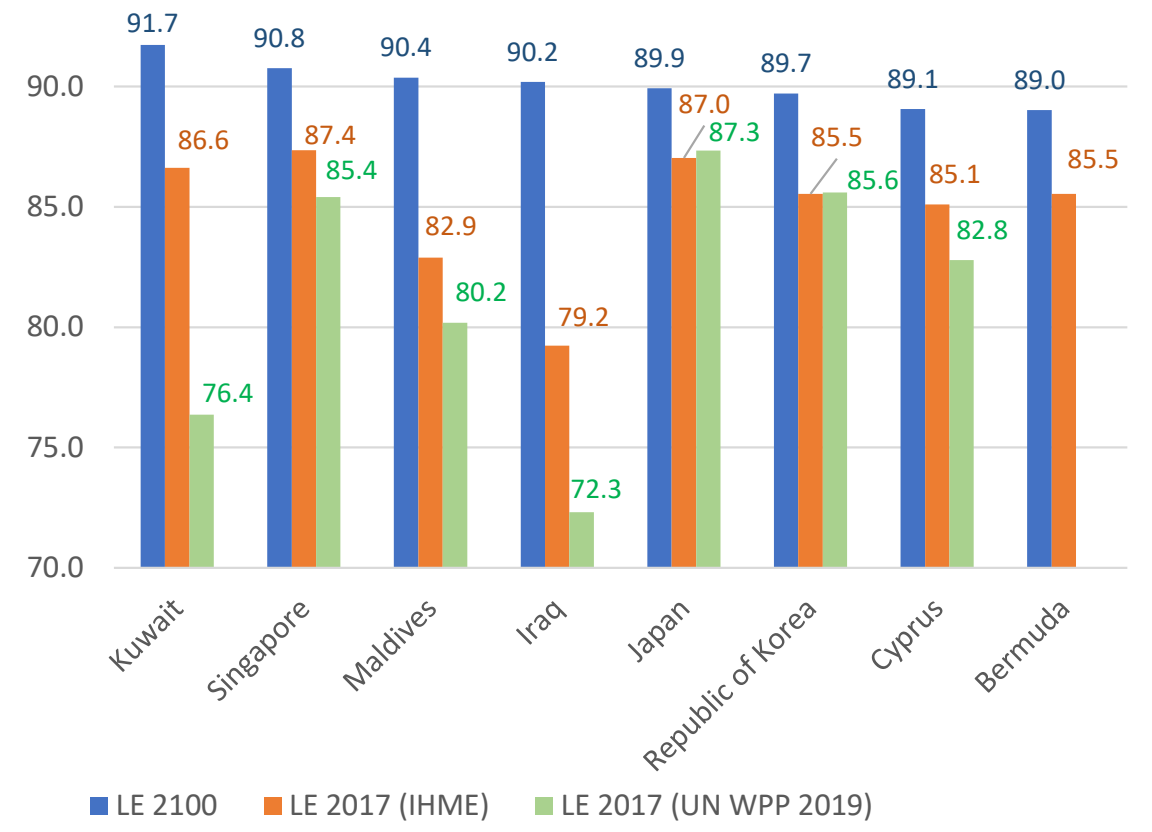


Figure 18: Estimated (1990-2017, IHME data) and projected (2018-2100) life expectancy at birth among women in selected countries (IHME Reference scenario)

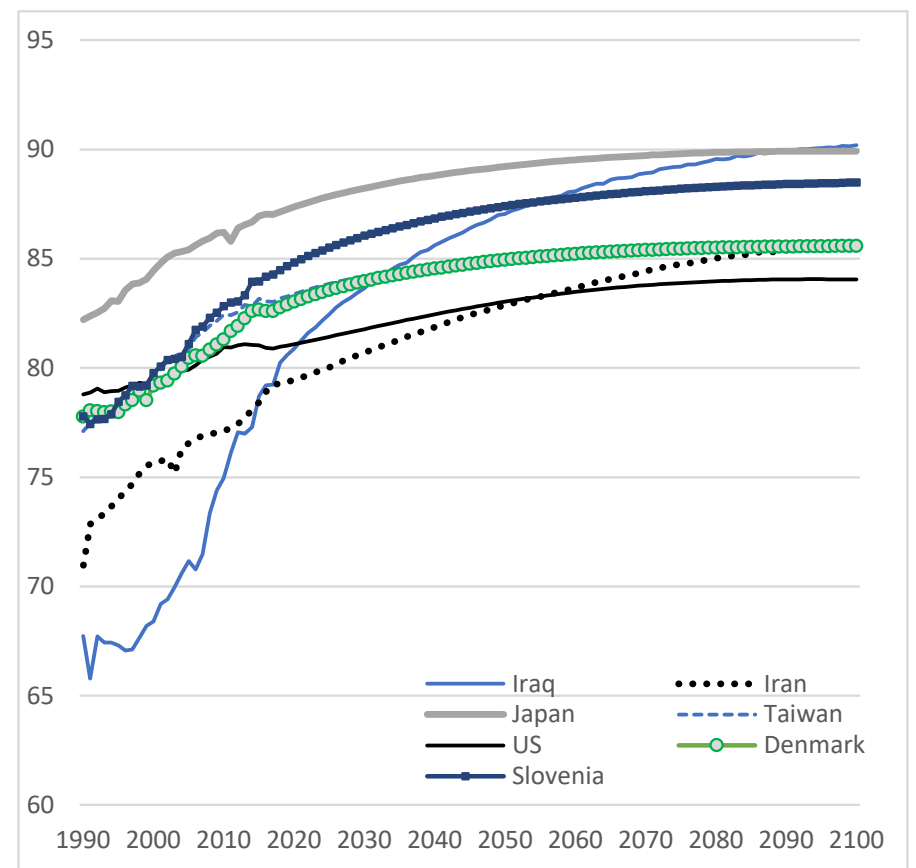

- Contrasting and inconsistent trends between countries

Similar to fertility scenarios, IHME mortality projections lack consistency in trends across broader groups of countries and regions. This is apparent when looking at the highest-ranking countries in projected life expectancy among women in 2100 according to the Reference scenario: the list includes an unexpected front-runner in longevity, Kuwait (projected life expectancy at 91.7 years), well ahead of the next country, Singapore (Figure 17). Iraq, which ranked $70^{\text {th }}$ in women's life expectancy at birth in 2017 (at 79.2 years according to the IHME estimate), is the projected star performer, with the highest life expectancy in 2100 after Kuwait, Singapore and Maldives, at over 90 years. Countries in broader regions are often projected to show contrasting trends and unexpected cross-overs, as illustrated in Figure 18 in the case of Iraq and Iran. Some countries like Iraq are expected to leapfrog ahead due to rapidly rising life expectancy, other countries including Slovenia show solid longevity improvements, while many other countries, including Taiwan, United States and Denmark, are projected to experience long-term life expectancy stagnation. These contrasting trends are probably driven much by the estimated recent trends in life expectancy during the last two decades, but they also point out that IHME projection model fails to bring consistent results across broader regions.

- Questionable estimates of mortality for the projection base year

Some of the odd projection results may stem from inaccurate data for the base year 2017, similar to fertility data discussed in Section 2.1 above. This is especially the case of Kuwait, where IHME estimated that life expectancy at birth among women in 2017 (86.62) exceeds by over 10 years the UNDP estimate of 76.36. A huge difference in the estimated data for 2017 is also shown in the case of the expected 
future frontrunner in longevity, Iraq, where IHME estimate of life expectancy among women, 79.24, is by 7 years higher than the UNDP estimate of 72.32. In countries with highest projected longevity globally, IHME estimates of life expectancy in 2017 are often well above the UNDP estimates for the same year (see Figure 17 for life expectancy among women). Only in two of these best-performing countries, Japan and South Korea, do the two data sources give identical estimate of life expectancy at birth.

\subsection{Migration scenarios}

Migration is the most volatile and least predictable component of population change. It is also most difficult to estimate and model: the need to balance population movements between countries so that these movements sum up to zero when analysed globally further complicates migration projectionmaking. To deal with these challenges national and international migration projections often assume either fixed levels of net migration or gradually diminishing net migration over time. In addition, many past projections had applied relatively conservative assumptions regarding long-term migration and the actual levels of international migration have often been underpredicted by projection-makers.

By comparison, IHME migration scenarios take a relatively bold approach of projecting migration using linear regression model, where net migration rate in each country is a function of natural population increase, Socio-demographic Index (SDI), and mortality from natural disasters, war, terrorism and legal interventions (Section 7 in Supplementary Appendix 1 to Vollset et al. 2020). Below we summarise what we perceive as the main weaknesses of IHME migration scenarios. We also cover issues we discussed in the case of fertility and mortality, such as inconsistent and implausible trends in individual countries and broader regions over time.

- Some of the determinants of migration are even more difficult to project than migration rates Overall, the regression model forecasting net migration rates covers factors tat are likely to have significant long-term impact on migration. However, forecasting some of these drivers of migrationespecially mortality rates from external causes including violent conflicts and terrorism-is even more daunting than forecasting net migration. Because wars, conflict and terrorism might start or cease suddenly from one year to the next, their incorporation makes migration scenarios potentially yet more uncertain, unstable, and difficult to comprehend. To understand projected ups and downs in migration in a country requires studying projected ups and downs in mortality from external causes of deaths, which themselves are modelled on the bases of projected trends in SDI and selected additional drivers. Moreover, the regression model for net migration is based on the observed data for 1990-2017 (and giving more weight to the more recent observations), a relatively short period compared with the long projection horizon. 


\section{- "Runaway" levels of confidence intervals in some countries}

The IHME model rightly indicates high levels of uncertainty in migration scenarios, constructing wide confidence intervals around the point estimates of projected future net migration. However, in some countries, these confidence intervals appear overblown, probably due to the recent history of conflictdriven migration. For instance, projected Cl_95 for net migration in Afghanistan in 2100 spans from 2.59 million to +1.96 million, implying that relative net migration would range from $-2.0 \%$ to $+1.5 \%$ in that year. This contrasts with much narrower range of migration scenarios for neighbouring Iran (which has much larger population). Similar widening on the uncertainty range in future net migration occurs in Peru, where it contrasts with relatively stable confidence intervals in the neighbouring Bolivia (Figure 19). The differences between these two countries in uncertainty range in net migration are way larger than the differences in their population size. ${ }^{14}$

\footnotetext{
${ }^{14}$ Projected population in the IHME Reference scenario for 2100 reaches 15.82 million in Bolivia and 39.34 million in Peru.
} 
Figure 19: Projected net migration (point estimate and 95\% confidence interval) in Afghanistan and Iran (upper panel) and Bolivia and Peru (lower panel)

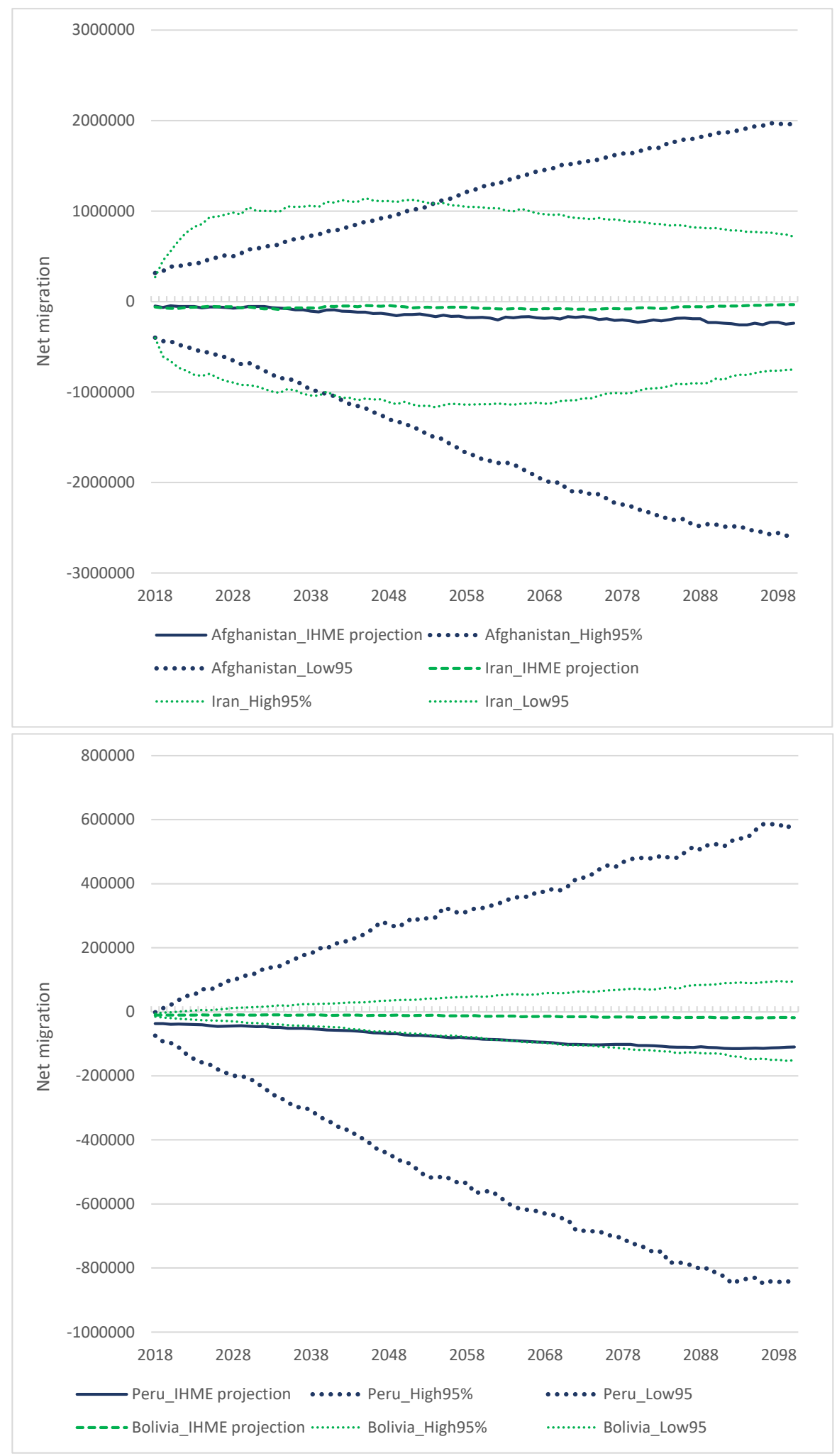


- Contrasting and inconsistent trends in net migration within broader regions

Similar to the scenarios of fertility and mortality, projected net migration trends often depict contrasting developments in neighbouring countries and countries within broader regions. Some territories which appear to have much in common geographically, economically, socially, politically, and demographically embark on completely different migration trajectories (e.g., the Gulf states). Other changes appear counterintuitive according to the conceptual framework which the paper ascribes to, namely a strong link between population and economic development. Consider the Philippines, for example. According to the paper, the country would jump up to 35th position in the global GDP rankings, then up to 24th by 2050 and 18th by 2100 . Yet, over the same period the negative net migration rate is set to rise from $-124,000$ in 2018 to $-189,000$ by 2050 and $-253,000$ by 2100 (the second largest 'deficit' in the world after Somalia). If we place our faith in GDP as an indicator of the economic wellbeing of a country, why would so many Filipinos choose to leave? The migration trajectories of some countries require further inspection and could benefit from some clarification in order to answer questions concerning consistency and underlying narratives. What, for example, could be the qualitative storyline which accompanies the net migration rate in North Korea jumping from $-2,170$ in 2018 to $-27,800$ in 2050 and then falling to $-6,720$ by 2100 ? What would change in Iraq to give it one of the largest net migration rates in the world by 2050 ?

We illustrate broader regional inconsistencies in projected net migration on the example of three countries from the Middle East and Central Asia (Afghanistan, Iraq, Iran) and three countries in Latin and Central America (Haiti, Jamaica and Peru). Iraq, a country suffering from economic, political and social instability, is projected to experience substantial inflows of population throughout the century. In contrast, Afghanistan is expected to see continuous strong outmigration during the next eight decades (Figure 20). Not surprisingly, Haiti, the poorest country in Latina and Central America, is expected to experience continuous outmigration. But the projected deepening negative migration saldo in Peru, which contrasts with positive net migration in some other countries with comparable levels of development like Jamaica, is a mystery that is difficult to comprehend. Furthermore, the IHME scenarios often depict sudden reversals, ups and downs in net migration over time. These may result in countries with initially very different net migration trends and levels ending up with similar projected net migration trajectory since the mid-century, as in the case of Israel, Spain, and Madagascar (third panel in Figure 20). Sudden reversals in projected net migration are neatly illustrated for Nigeria, were net migration turns from negative to positive in 2037, then shoots up to much higher levels in 2040s-2050s and later turns negative again at the end of the century. 
Figure 20: Projected net migration in selected countries, IHME scenarios for 2018-2100

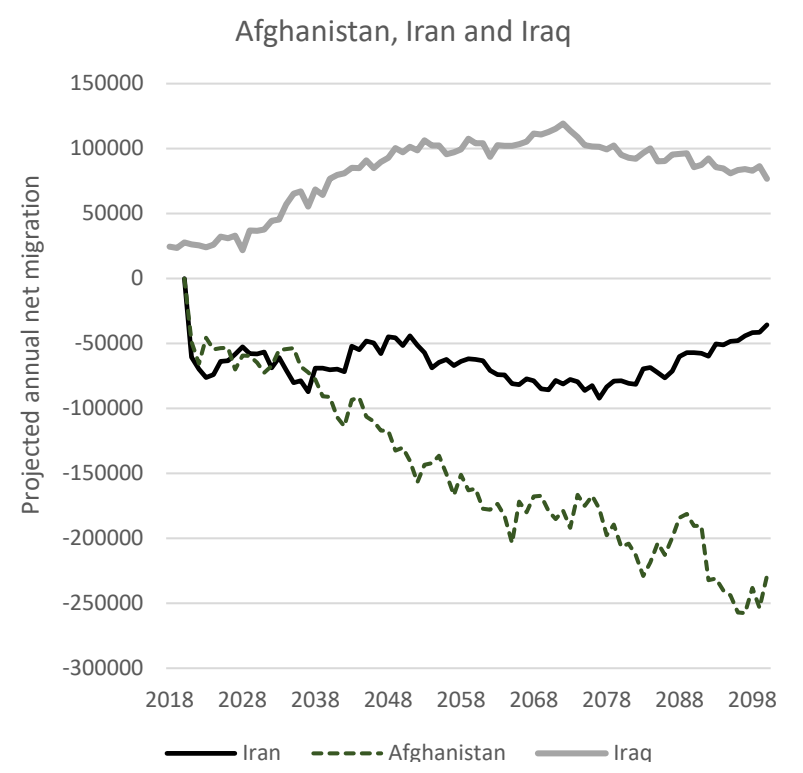

Israel, Madagascar and Spain

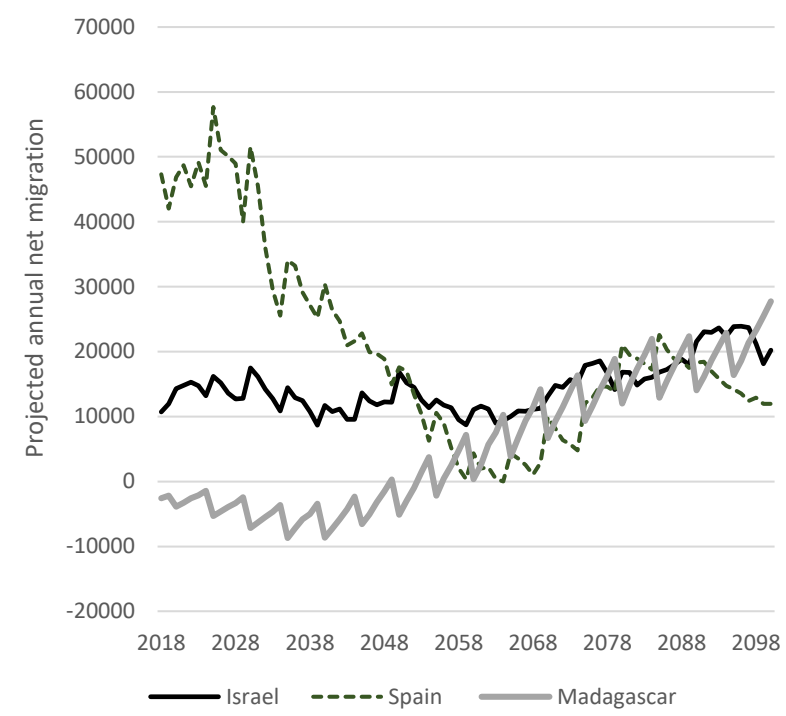

Haiti, Jamaica and Peru

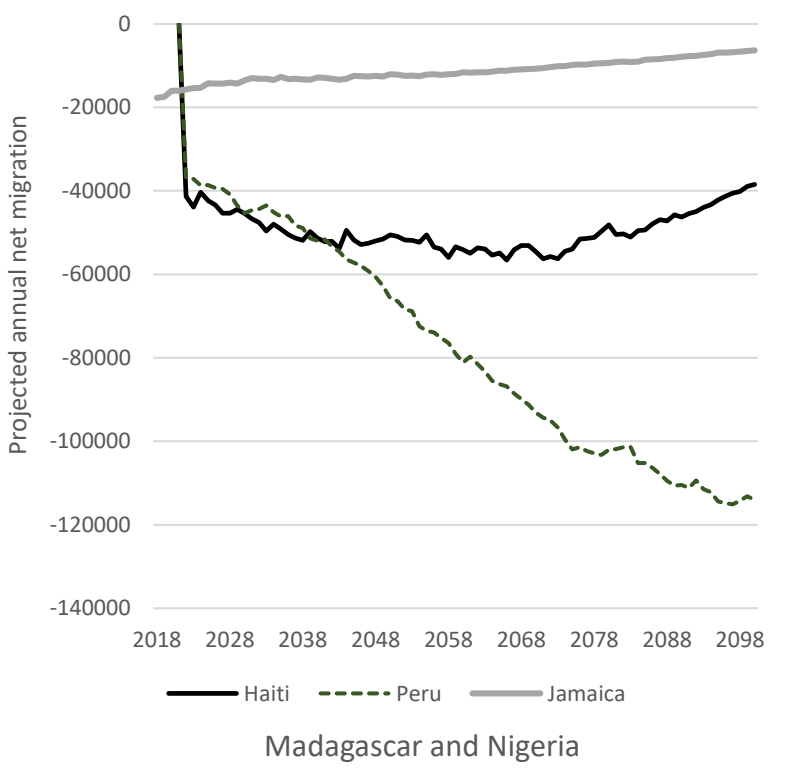

150000

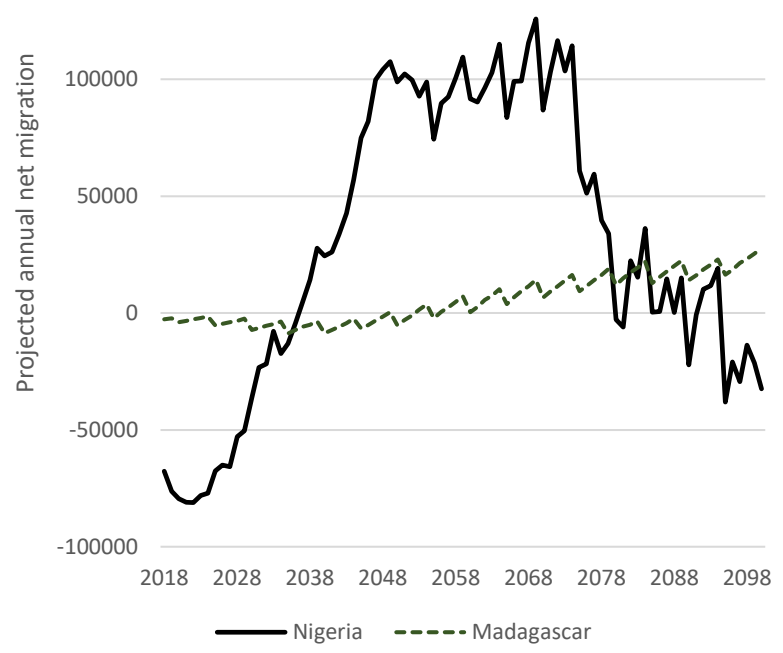

\section{Projected long-term decline in net migration}

For most countries the IHME migration projection implies gradually diminishing levels of net migration in the course of the $21^{\text {st }}$ century. This may appear as a reasonable expectation given vast uncertainty about future migration, but this expected development may eventually distort projected population trends in higher-income countries with relatively high rates of immigration in the past decades. In other words, IHME projections may underestimate future levels of net migration, inflate future population declines and the pace of population ageing in high-income, low-fertility countries with high immigration rates. Moreover, the mismatch between the estimated net migration in the 
past two decades (2000-2019) and the projected future net migration differs widely by country, possibly amplifying cross-country differences in future population trends (Table 1). For instance, across 17 larger countries in Western, Northern, Southern and Central Europe projected net migration in 2020s-2030s amounts to about two thirds of the estimated net migration in these countries in 2000-2019, with the ratio diminishing to 35\% in the last two decades of the century. By contrast, projected levels of net migration relative to observed net migration in 2000-2019 are much lower in Southern Europe, at 22\% in 2020-2039, falling further to $11 \%$ in 2080-2099. In the case of Spain, projected migration in 2080-99 drops to only 6\% of the level recorded in 2000-2019 (Table 1). This might be due to IHME model putting more weight in the more recent data, when migration to Southern Europe was unstable and disrupted by the financial crisis in 2008-13 and its aftermath. However, by potentially underestimating future net migration to the region by a wide margin, the IHME scenarios are likely to give an overblown picture of negative population trends in the region. 
Figure 21: Observed (1990-2017) and projected (2018-2100) net migration in Europe (17 selected countries) and in Southern Europe, IHME scenarios

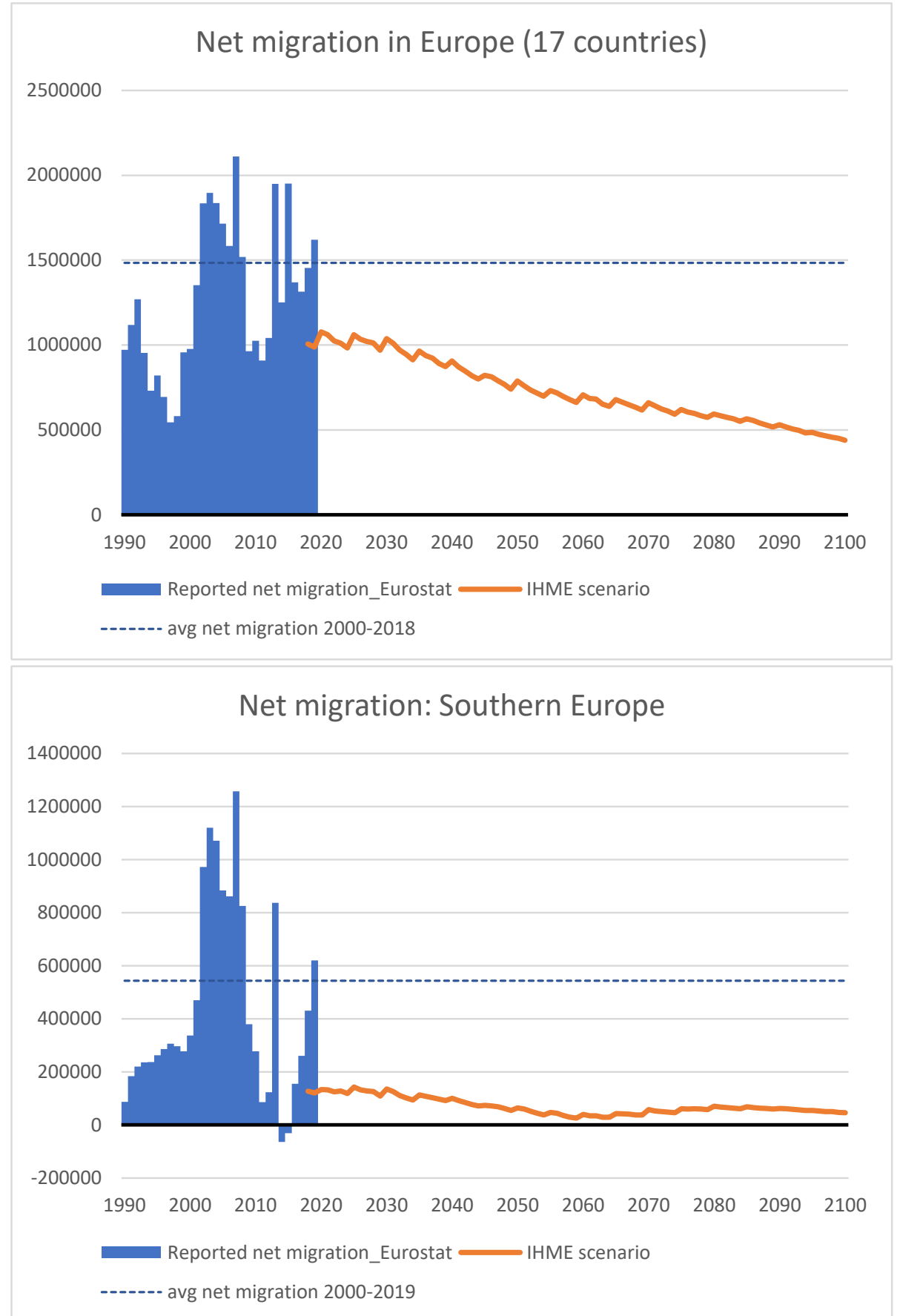

Note: Countries included in the analysis are listed in Table 1 below. 
Table 1: Projected average annual net migration in selected countries and regions in Europe in 2020-2039 and 2080-2099 relative to the observed average net migration in 2000-2019 (IHME migration projection)

\begin{tabular}{|c|c|c|c|}
\hline & $\begin{array}{c}2000-19 \\
\text { (observed) }\end{array}$ & $\begin{array}{c}2020-39 \\
\text { (projected) }\end{array}$ & $\begin{array}{c}2080-99 \\
\text { (projected) }\end{array}$ \\
\hline German-speaking & 100 & 111.7 & 42.1 \\
\hline Austria & 100 & 50.0 & 23.4 \\
\hline Germany & 100 & 127.9 & 47.8 \\
\hline Switzerland & 100 & 78.0 & 28.2 \\
\hline Western Europe & 100 & 78.9 & 54.4 \\
\hline Belgium & 100 & 101.6 & 62.5 \\
\hline France & 100 & 103.1 & 78.2 \\
\hline Ireland & 100 & 28.8 & 19.1 \\
\hline Netherlands & 100 & 42.8 & 23.7 \\
\hline UK & 100 & 77.3 & 53.5 \\
\hline Nordic countries & 100 & 87.4 & 55.6 \\
\hline Denmark & 100 & 89.5 & 60.6 \\
\hline Finland & 100 & 117.9 & 62.5 \\
\hline Norway & 100 & 103.0 & 58.1 \\
\hline Sweden & 100 & 72.6 & 51.5 \\
\hline Southern Europe & 100 & 21.7 & 11.0 \\
\hline Greece & 100 & 146.7 & 64.5 \\
\hline Italy & 100 & 30.2 & 15.9 \\
\hline Portugal & 100 & -31.1 & 14.5 \\
\hline Spain & 100 & 14.0 & 5.8 \\
\hline Czechia & 100 & 46.7 & 35.3 \\
\hline Europe - 17 countries & 100 & 66.5 & 35.2 \\
\hline
\end{tabular}




\section{CONSEQUENCES}

We now focus on some of the consequences of IHME projections as discussed in the Lancet article by Vollset et al. and in the media. In adopting an approach which hastens fertility decline, the article engages strongly with three core areas which attract popular attention: climate change, and the narratives relating to population growth/decline and ageing.

\subsection{Climate change}

Our forecasts for a shrinking global population have positive implications for the environment, climate change, and food production [p. 2 in Vollset et al. 2020]

Fewer people on the planet in every year between now and 2100 than the number forecasted by the UNPD would mean less carbon emission, less stress on global food systems, and less likelihood of transgressing planetary boundaries. [p. 17 in Vollset et al. 2020]

The quote above represents a very clear statement of the author's implication of the findings of their projection exercise. However, this line of thinking arguably adopts an overly-deterministic view of the relationship between population size and factors associated with carbon change. There is a long and enduring debate about the interaction between such issues in both the scholarly and more popular literature - so much so that an overview is neither necessary nor feasible here (O'Neill et al. 2010; Emmott 2013; Dorling 2013; Gray 2013). Suffice to say, though, that there is a significant divergence between the 'demographic deterministic' approach, versus the 'behaviour and technological advancement' approach; and such divergence of opinion is not adequately represented in the paper.

The British conservationist Sir David Attenborough once famously remarked that he had 'never seen a problem that wouldn't be easier to solve with fewer people, or harder, and ultimately impossible, with more' (BBC 2009). The logic of this is certainly appealing. However, this is still a significant step away from simply equating fewer people to 'less carbon emission'. As we will return to in the final section, this over-simplistic approach may be unhelpful in shaping the conversation regarding population and, in this case, climate change and sustainable development.

\subsection{Population decline and ageing}

Although good for the environment, population decline and associated shifts in age structure in many nations might have other profound and often negative consequences [p.17].

Perhaps the most striking assertions in the paper (and the media dissemination) relate to population decline and the consequences thereof. The projected change in total population size is itself one of the 
projection outcomes that shows characteristic inconsistencies and implausible trends between countries and regions, both in the magnitude of the expected population shifts, but also in the width of the projected uncertainty. For instance, the list of countries with expected population declines by $50 \%$ or more between 2018 and 2100 according to the Reference scenario includes European countries that have experienced sizeable population shrinking in the last three decades such as Latvia, Moldova, Ukraine, Bulgaria and Romania, as well as more ;surprising' predicted hotspots of depopulation in other world regions such as United Arab Emirates, Sri Lanka, El Salvador, and Jamaica (Figure 22). On the extreme side, Latvia's population is expected to shrink by $78 \%$ by the end of the century, with Cl_95 ranging from a $60 \%$ to $89 \%$ fall in population size. ${ }^{15}$ Arguably, the most glaring contrasts in projected population trends are found in Middle East, where neighbouring countries with similar levels of economic development are often expected to follow contrasting population trajectories. The population in the United Arab Emirates is projected to shrink by $65 \%$ by 2100 , whereas that of Saudi Arabia is expected to shrink by $6 \%$, the population of Kuwait is projected to grow by $5 \%$ and that of Bahrain by $24 \%$ (Figure 22). The population of Syria and Iran is projected to fall between now and the end of the century, whereas that of Iraq and Israel is projected to experience rapid increase, amounting to $143 \%$ and $165 \%$, respectively, by $2100 .^{16}$

\footnotetext{
${ }^{15}$ This "leading" position of Latvia is somewhat surprising given that it is a middle-income member of the European Union (with a GDP level well above many South-Eastern and Eastern European countries), which is not currently suffering from unrest, territorial or military conflict (unlike, for instance, Ukraine), or from extreme climate change, dysfunctional government or economic collapse.

${ }^{16}$ Furthermore, it is difficult to interpret predicted uncertainty intervals, which can vary greatly even for countries with comparable population size and projected population trends in the reference scenario, such as Qatar (Cl_95 for total population change between 2018 and 2100 ranging from - $42 \%$ to $+17 \%$ ) and Kuwait (Cl_95 from -38\% to $+158 \%)$.
} 
Figure 22: Projected change in population size between 2018 and 2100 according to IHME Reference scenario (point estimate and 95\% uncertainty interval)

Countries with projected population decline by $50 \%$ or more

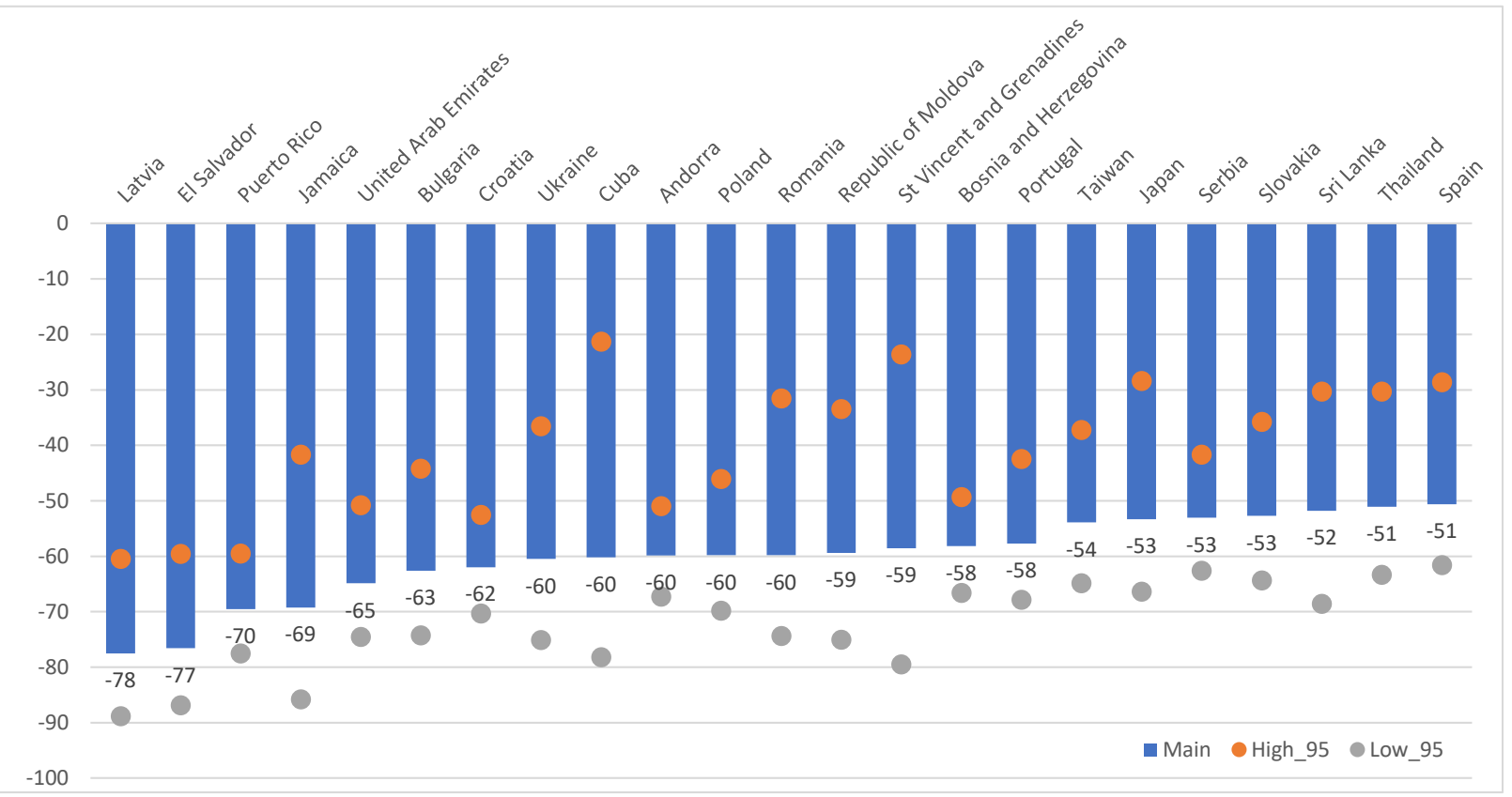

Selected Middle East countries

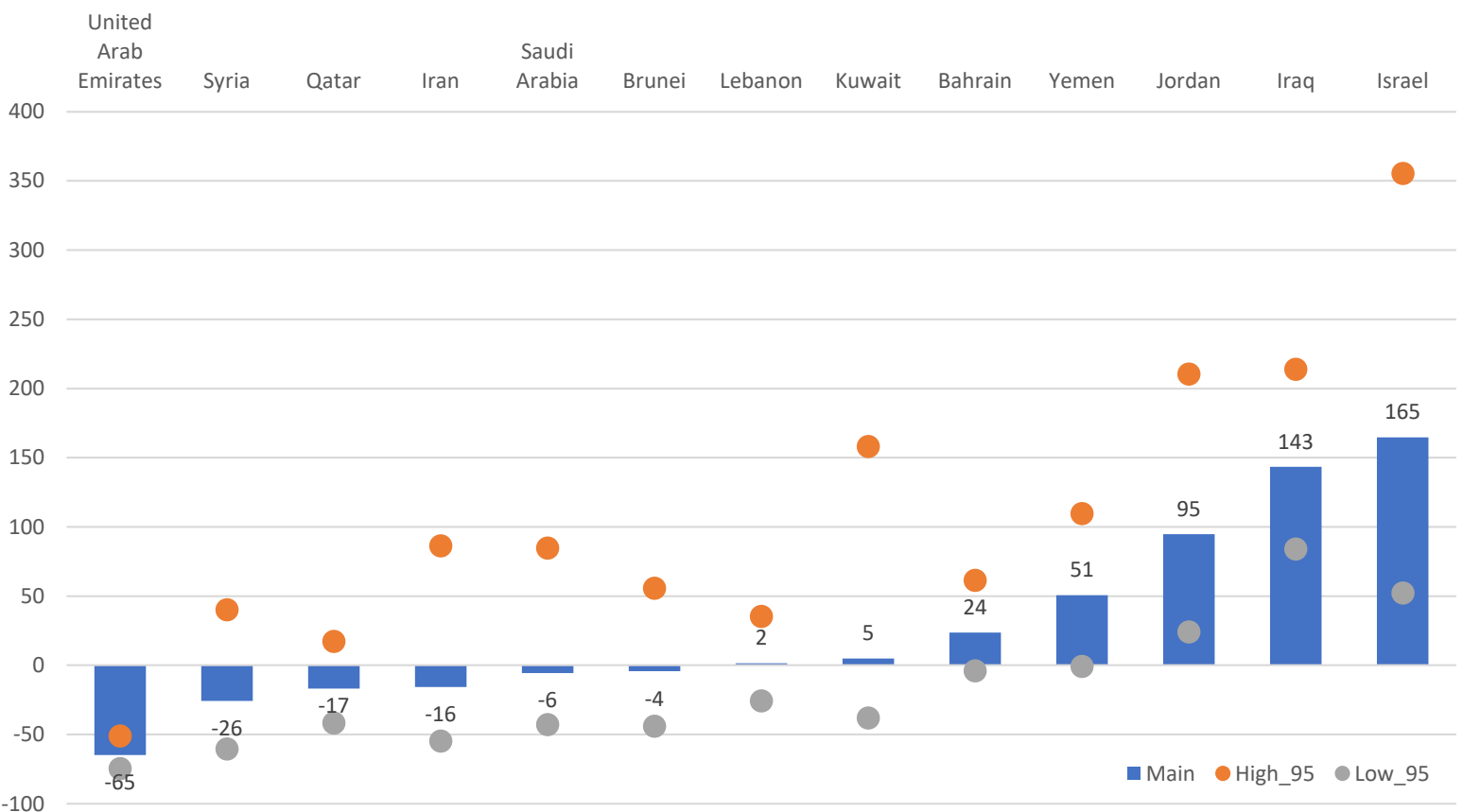


Vollset et al. present forecasts of total GDP by country, which are determined by the "number of working-age individuals", defined as people aged 20 to 64 . This simplistic view ignores long-term shifts in education, age at retirement, age-specific productivity and technology that are likely to make this definition of working age population obsolete (e.g., Lee et al. 2014).

Of course, population size plays a key role in determining GDP and such forecasts are discussed in Vollset et al. study. ${ }^{17}$ The authors state that "Although GDP is not the only determinant of global political influence and power, it is a crucial factor" [p. 18], and that "Some historians argue that the size of economies translates into geopolitical power" [p.18]. ${ }^{18}$ Furthermore, "Geopolitical power is also linked to military might and, at least for now, armies require individuals to serve in them" [p.18]. In this vein, in the context of the forecast changes in population the paper concludes that "Russia and Brazil's relative ranking of GDP would decline moderately, whereas Spain and Italy would see substantial declines. Nigeria would increase considerably" [p.18].

This link between population growth, GDP and geopolitical power is made even more explicitly in the interactions with the media. Reflecting on the findings of the study, Dr Richard Horton, editor of The Lancet observed that "Africa and the Arab World will shape our future, while Europe and Asia will recede in their influence (...) By the end of the century, the world will be multipolar, with India, Nigeria, China, and the US the dominant powers" (Meredith 2020).

In essence, there is nothing especially controversial about this narrative. It is simply a repetition of the well-worn arguments which link population growth to GDP and, in turn, to geopolitical power; and to infer that the transition to older populations is a uniformly negative phenomenon. As the authors rightly infer, this "demographic enfeeblement" narrative has been "called attention to" by "popular authors and political commentators (...) for well over a 100 years" [p.18]. ${ }^{19}$ However, these causal mechanisms have been increasingly problematised in the academic literature in recent years. Population decline itself has been reappraised and discussed in a much broader context in literature ignored by the paper (Coleman and Rowthorn 2011), which rather relies on one book written by non-specialists (Bricker and Ibbitson 2019). The use of GDP as an indicator of the economic well-being of nations is increasingly being questioned, for example, by Ivković (2016) and Dynan and Sheiner (2018); and we are witnessing the retreat of 'GDP fetishism' as Joseph Stiglitz (Stiglitz 2009) refers to it. There are also many alternative perspectives on the primary determinant(s) of geopolitical power beyond GDP (Beckley 2018; Giblin 2013) and certainly population size (Coleman and Basten 2015). In other words, to assert the absolute

\footnotetext{
${ }^{17}$ The GDP forecasts [p.11] are derived from an article produced by the GBD team on global health financing (Global Burden of Disease Health Financing Collaborator Network 2019). No justification for the use of these GDP forecasts are given, nor are readers pointed to alternative GDP forecasts.

18 'Some historians' here refers to one book, The Human Tide: How Population Shaped the Modern World published by Paul Morland, an associate research fellow at Birkbeck College, London. According to his literary agent ('CMA Creative Management'), Morland is "an authority on the interfaces between nationalism, ethnicity and demography".

${ }^{19}$ In Vollset et al.'s text, two books are cited, Bricker and Ibbiston (2019) and Morland (2019). Other examples include (Longman 2004; Wallace 2001; Last 2013)
} 
predominance of certain regions and territories such as 'the Arab World' and 'Nigeria' based upon the conceptual link between working-age population size and economic performance - without considering the technical issues surrounding the production of such figures - is highly problematic.

Of course, the mirror of this 'demographic enfeeblement' narrative relates to population ageing. The IHME approach to ageing is characterised by a fixation on chronological age, with 65 conceptualised as a sharp divide between 'working age' and 'older population'. Vollset et al. [p. 16] stress that "High-income countries were forecasted to accentuate the inverted shape of the age pyramid, with strong absolute decreases in the population younger than 65 years and absolute increases in the population aged 65 years or older under all scenarios". Such 'accentuated inverted age pyramids' were forecast to be found in other world 'super-regions' including South Asia, Southeast Asia, East Asia and Oceania, and Latin America and the Caribbean.

These changes are then translated into negative consequences for society and the economy. In macroeconomic terms, "With all other things being equal, the decline in the numbers of working-aged adults alone will reduce GDP growth rates" [p. 17]. In certain countries such as India and China, "huge declines in the number of workers were forecasted, alongside steady increases in Nigeria" [p.16]. Furthermore, "having fewer individuals in these age [younger] groups might reduce innovation in economies, and fewer workers in general might reduce domestic markets for consumer goods, because many retirees are less likely to purchase consumer durables than middle aged and young adults" [p17].

As the authors state, "in countries with slower economic growth and with rising shares of the population who are retired compared with those who are still working, the fiscal sustainability of national health insurance and social security programmes will be challenged" [p.18]. These increases in the "dependency ratio' (not clearly defined), can then lead to the following 'Doomsday' scenario:

Taxation rates required to sustain national health insurance and social security programmes might be so large as to further reduce economic growth and investment. Insecurity from the risk that these programmes could fail might generate considerable political stress in societies with this demographic contraction. Fiscal sustainability will add profound political pressure on governments to address the challenge of population decline [p. 18].

These concerns regarding population decline and ageing in the paper were widely disseminated in the media. In a quote to the BBC, CM referred to the "inverted age structure (more old people than young people) and all the uniformly negative consequences of an inverted age structure" (Gallagher 2020). He continues that the projected population changes, especially related to ageing,

'will create enormous social change. It makes me worried because I have an eight-year-old daughter and I wonder what the world will be like ... Who pays tax in a massively aged world? Who pays for healthcare for the elderly? Who looks after the elderly? Will people still be able to retire from work? (Gallagher 2020) 
In quotes to Al-Jazeera, CM stated that "most countries outside of Africa will see shrinking workforces and inverting population pyramids, which will have profound negative consequences for the economy" (Al-Jazeera 2020). More directly, CM told The Guardian "When there's tons of people over 80 and very few under 30, everything gets totally scrambled" (Safi 2020).

This interpretation of the phenomenon of population ageing is deeply problematic on a number of levels.

Firstly, the conceptual and methodical basis of the calculations of ageing are flawed. The paper generally refers to 'working-age adults' as being aged 20-64. ${ }^{20}$ This is held constant over time (from 1950 to 2100) and for all territories of the world. The paper also makes an explicit link between working-age adults and the labour force. For example, the authors state that "we plotted the forecasted number of working-age individuals (aged 20-64 years) for the ten largest countries in 2017, in the reference scenario ... Huge declines in the number of workers were forecasted in China and India, alongside steady increases in Nigeria" [p.16].

This simplistic approach ignores recent views concerning the universal, unchanging application of certain 'boundaries' to 'old-age' (Sanderson and Scherbov 2019) 'Fixing' these boundaries of 'old-age' as constants over 150 years and for all countries of the world effectively states that a 65-year old man in Sierra Leone shares the same characteristics as a 65-year old female in Japan today - or even in 2100 (Dorling and Gietel-Basten 2017). Such measures in turn obscure various changes in human capital over time - primarily in health and education (Lutz 2013). As we will discuss in the next section, this not only misrepresents the nature of population ageing over time, but may effectively narrow down policy responses to it. In sum, the changing characteristics of any given population must be taken into account when attempting to determine the potential challenges of population ageing. As Sanderson and Scherbov (2019: 229) aptly argue, when taking people's characteristics into account, "tomorrow's 65year-olds will not be like today's 65-years-olds; they will be functionally younger."

Secondly, there is an increasingly critical appraisal of the very notion of 'dependency' (Sanderson and Scherbov 2015) and its general application in all parts of the world (Gietel-Basten 2018). The concerns set out above regarding redistribution of resources from 'working' to 'retired' populations relating to social security programs and 'national health insurance programs', primarily financed through taxation are relevant only to the part of the world which has such systems, but also ignore the much more complex system of intergenerational transfers in all countries (Lee and Mason 2012; Lee et al. 2014). The link in the paper between 'working age' and 'working' (and the definition of work itself), as well as 'non-working' and 'dependent' and 'retired' is highly simplistic, if not naive. In other words, when determining the impact of ageing in any given setting, the institutional framework of any given setting and its flexibility and capacity to adapt - will be critical in shaping any responses to population ageing.

20 We say 'generally', because in one part of the paper the ILO definition of all individuals aged 15 years or older is deployed [p.18]. Later on the same page, a further alternative of 15-74 is implicitly expressed. 
Thirdly, the notion of a 'uniformly negative' consequence of population ageing is problematic. As intimated above, an ageing population is, in itself, a neutral change. The only impact - positive or negative - is derived from the economic, political, health and social systems which interact with these changes. From a normative perspective, though, the simplistic expressions of these 'negative consequences' - especially in the quotes presented to the media - simply add to an underlying ageist narrative in both public and policy discourse (Dick 2016), which is profoundly unhelpful in the context of bringing about the institutional reforms required to adapt to a changing population structure. Finally, this negative approach ignores the literature on various aspects of ageing which can be associated with positive outcomes, such as the so-called 'second demographic dividend' (Mason and Lee 2006). In this vein, the notion that "fewer workers in general might reduce domestic markets for consumer goods, because many retirees are less likely to purchase consumer durables than middle aged and young adults" (p.17 in Vollset et al. 2020) ${ }^{21}$ is based upon a highly partial, static view of consumer markets which is highly likely to change over time. This is summarised in the study by Lee et al. (2014) based on the National Transfers Accounts published in Science:

Many factors will influence the economic effects of low fertility that are not part of the formal model used in the analysis. However, these additional considerations reinforce the basic conclusion that low fertility is not a serious economic challenge. The effect of low fertility on the number of workers and taxpayers has been offset by greater human capital investment, enhancing the productivity of workers.

We return to these issues in the next section on 'responses' to the forecasts.

\section{RESPONDING TO POPULATION DECLINE}

The foregoing section, then, clearly sets out how Vollset et al.'s paper (and the representations of the authors and their proxies to the media) paints population decline and ageing as a uniformly negative phenomenon. In this context, they state that "As nations come to recognise the challenges of fertility rates lower than the replacement level and the potential for demographic contraction, they have four options to pursue" [p.18]. In this section we address each of these four options in turn. It is an irony that the IHME team - while outlining these options - probably does not have much confidence in their effectiveness or in the ability of governments to implement them, as they would otherwise be at least partly incorporated in the presented projection scenarios.

\section{1. "Attempt to increase the fertility rate by creating a supportive environment for females to have children and pursue their careers"}

Here, the authors correctly claim that "several governments have pursued explicit policies to increase fertility rates" [p. 18] - elsewhere, explicitly referred to as 'pronatalist policies' designed to "yield (...)

${ }^{21}$ Once more, the only citation for this claim is the book by Bricker and Ibbitson (2019) 
increases in the birth rates" [p.19]. Yet, the examples chosen are rather unusual. They state that "Some, such as Sweden, Singapore, and Taiwan (province of China), have tried to create positive environments that facilitate females choosing to have more children" [p.19]. Again, these are all true; but both the contexts of these different population and welfare systems, and the motivations for the different territories are completely different. Swedish family (and labour, gender, welfare) policy certainly has pronatalist roots which can be traced back to the 1930s (Pendleton 1978). However, the extent to which contemporary Swedish family policy is explicitly 'pronatalist' in motivation is problematic. Vollset et al. (2020) state that "Sweden has seen an increase in its TFR from 1.5 in the late 1990s to 1.9 in 2019, although the country's CCF50 has been much less affected" [p.18]. ${ }^{22}$ It is hard to see the point of this (imprecise) example, given what we know of the unstable "roller-coaster" fertility in Sweden, partly driven by changes in the timing of births ('tempo effect') and its relatively flat cohort fertility rates. Then the authors correctly state that "incentives have had little effect in Singapore and Taiwan (province of China)" [p.18].

We argue that to distill policy initiatives to support families down to three examples is partial at best, and highly simplistic at worst (Thévenon 2011; Gietel-Basten 2019). Conceptually, too, it is highly problematic to equate all family policies with pronatalist policies; to suggest that policies for females to 'to have children and pursue their careers' are some kind of panacea; and, of course, to concentrate only on the reproductive (and other) aspirations of women. ${ }^{23}$ In other words, a more complex, holistic view of low fertility - and the relationship between fertility aspirations and outcomes (Gietel-Basten 2019; Casterline and Gietel-Basten 2018; Bongaarts 2001) - can help understand in what ways governments, employers, families and other involved parties can support women and their partners to meet their family and reproductive aspirations for their own sake, and not for the purpose of some externally defined population target (Gietel-Basten 2019).

\section{2. "Restrict access to reproductive health services"}

The authors correctly state that "Unfortunately, some countries have in the past sought to increase the total fertility rate by restricting access to reproductive health services" [p. 18]. The examples given here are "the banning of abortion in Romania in 1966 and in the Soviet Union from 1936 to 1955" [p.19]. They continue that " $A$ very real danger exists that, in the face of declining population, some states might consider adopting policies that restrict female reproductive health rights and access to services" [p.18].

It is not necessary, however, to travel back to mid-1960s Romania to identify cases of governments restricting access to reproductive health services (or, on the other hand, effectively penalising nonchildbearing) in the name of meeting some population target or other ideological issue. Recent

\footnotetext{
${ }^{22}$ Yet again, the only citation given here is to the book by Bricker and Ibbitson (2019). The data by Statistics Sweden (2020) show that the TFR in Sweden indeed increased from 1.5 to 1.9 between 1999 and 2010 (not 2019), thereafter retreating to 1.7 in 2019.

${ }^{23}$ This naive approach to gender (roles) and reproduction is reflected in the following quote in a BBC article (Gallagher 2020) where in response to low fertility rates in places such as Singapore, CM states "I find people laugh it off; they can't imagine it could be true, they think women will just decide to have more kids".
} 
examples such as the restrictive policies enacted in Turkey (MacFarlane et al. 2016) and Iran (Kokabisaghi 2017) are not referred to in the paper. In China, a proposal to 'tax' the childless was recently proposed by academics at Nanjing University (Tin-yau 2018).

In both the paper and various statements to the media the authors rightly share their concerns about this possible policy direction, and the fact that "Low fertility in these settings might become a major challenge to progress for females' freedom and rights" [p.18]. However, we argue that it is precisely for these reasons that we should be ever more circumspect in our methods and communication of projections. In a BBC article, concerning a 'global crash in the number of children being born' for example, CM referred to "jaw-dropping fertility" (Gallagher 2020). Without the context that the particular model and assumptions chosen themselves result in such a crash, the confidence of the projections and the message in the media is clear. In other words, projections are active agents in shaping the future trajectory of populations themselves (Gietel-Basten 2019). As such, if not communicated properly the projections can generate or exaggerate precisely the concern (about population decline, for example) which they themselves express worry about. In other words, projections may become a self-fulfilling prophecy.

\section{3. 'Increase labour force participation especially at older ages'}

Vollset et al. note that "A short-term solution to declining working-age populations is to increase labour force participation" [p.18]. They continue that "many societies that do not choose immigration as a strategy will probably try to increase labour force participation as a temporary strategy" [p.18]. This is odd that immigration and increasing labour force participation are somehow exclusive and incompatible - but we return to the issue of migration below. "However," they continue, "such increases [in labour force participation ratios] are not a long-term solution because once the higher labour force participation rates are achieved, the inexorable decline in population numbers, even in those aged 1574 years, will eventually manifest unless stabilising forces are implemented" [p.18]. Apart from taking into account the differences between countries, this statement returns us to the fundamental issue raised above that population decline (and decline in the total size of the labour force) - which will, of course, be defined in different ways, formally and informally, around the world - is bad.

Again this represents a very narrow view of the issues relating to population decline and ageing which is elsewhere presented as such a threat. The authors indeed state that "In the future, technological advances might provide a solution to the decline in the workforce", and that "developments in robotics and artificial intelligence...could substantially change economic growth" [p.18]. But in addressing the challenges of population ageing and decline, we must surely look beyond the nexus of technology and economic growth (or working until you die). We need to reform existing social welfare and pensions systems and design ones for the future which are sustainable. We need to maximise the potential human capital of all in terms of economic productivity and health at all stages of life (WHO 2018; Paúl, Ribeiro, and Teixeira 2012) in order to harness the potential benefits of 'demographic metabolism' (Lutz 2013). Returning to an earlier point, part of this can be based upon changing the measurements of ageing, and how a revolution in human characteristics over time and massive differences in those 
characteristics over space are not encompassed by fixed, chronological boundaries to old age (GietelBasten 2018).

\section{Promote immigration}

According to Vollset et al., "For high-income countries with fertility rates lower than the replacement level, the most immediate solution is liberal immigration policies". They continue that "the optimal strategy for economic growth, fiscal stability, and geopolitical security is liberal immigration with effective assimilation into these societies" [p.19]. These statements require some unpacking. First, there is an unintended contradiction between these statements and the presented IHME projection scenarios, with only one migration scenario, which happens to assume a declining level of net migration into many highly developed countries (Section 2.4 and Figure 21 above). Second, apart from the arbitrary threshold of 'population replacement level' and ignoring the concept of population momentum, it is not clear why this should be relevant only to 'high-income countries' (Sander, Abel, and Riosmena 2014) - especially given that the projection parameters place ever more low- and middle-income countries into that category. Third, the concept of 'replacement migration' is not properly explored in the paper, and the necessary high number of migrants who would be required to maintain support ratios or prevent population decline are not debated (Coleman 2002; UNPD 2001). In a context of faster fertility decline and slower population growth, where would all of these migrants come from? Fourth, the notion of an 'optimal strategy' is narrowly defined in an economic sense, and grounded in a fundamental (and problematic) link between population size and geopolitical security.

There are also some confusing statements concerning the practical functioning of contemporary migrations. For example, Vollset et al. state that "although not the case in Canada, Australia, and New Zealand, liberal immigration policies in the USA have faced a political backlash in recent years, which threatens the country's potential to sustain population and economic growth" [p. 19, no citation]. Such immigration policies have certainly met with a 'political backlash' in many other countries including Australia (Gravelle 2019; McDonald and Markus 2020). Indeed, it may be harder to find countries where there has not been a political backlash to immigration than where there has (Gietel-Basten 2016).

The authors further state that "Japan, Hungary, Slovakia, the Baltic states, and others are facing substantial declines in population but have not adopted immigration as a compensating strategy. In these societies, so far, the desire to maintain a linguistic and culturally homogeneous society has outweighed the economic, fiscal, and geopolitical risks of declining populations" [p.19]. This statement requires some unpacking. Japan, without doubt, prizes its status as "a linguistic and culturally homogeneous society"; although a change in attitudes towards immigration is slowly coming about (Komine 2018), with the government employing careful semantics to slowly change entrenched systems (Roberts 2018). In Hungary, Slovakia, the Baltic states - and indeed many other settings - immigration policy (and resistance to it) is shaped by much more complex factors than simply maintaining 'a linguistic and culturally homogeneous society'. Such factors include the prevailing political systems and narratives, the relationship to supranational institutions such as the EU, and the particular context of both national histories and the so-called 'migration crisis' in Europe in recent years. 


\section{CONCLUDING REFLECTIONS}

"Suddenly, we're now seeing this sort of turning point where it is very clear that we are rapidly transitioning from the issue of too many people to too few." Quote by CM in (Woodyatt 2020)

In this contribution, we have sought to assess the key contributions and weaknesses of the IHME population projections. We were motivated (or, perhaps, provoked) in part by the way Vollset et al. and $\mathrm{CM}$ presented their scenarios as superior to other projections, without acknowledging their weak points or exercising caution when interpreting their results. Especially in the media, but partly also in the Vollset et al. (2020) paper, strong and often unfounded claims and conclusions are drawn, almost in a tabloid style. At times, the authors seemingly "discover" the issue that has been debated by population researchers for decades - such as the topics of population ageing, low fertility, declining populations and their consequences, or, indeed, the fact that today's fertility is highly controlled and regulated - and then reinterpret it, often offering simplistic, misleading or exaggerated views. This casual approach to population issues and their drivers is reflected in numerous quotes by the authors in the media. For example, as CM told Al-Jazeera "Our analysis suggests that as women become more educated and have access to reproductive health services, they choose to have less than 1.5 children on average" (AlJazeera 2020). Meanwhile, in The Guardian, CM said “We've realised there's something different about our species, namely that women can control their fertility ... As they get more educated and have access to jobs and careers they choose to have fewer children than replacement requires" (Safi 2020).

Despite admirable breadth and scope of the IHME models combined with extensive statistical and modelling machinery behind their projection scenarios, we have identified many issues and inconsistencies that indicate IHME data and projections might not be as reliable and as superior to the other available projections as their authors suggest. The issues we identified range from what could be called 'unanswered questions' to internal inconsistencies, discrepancies and illogical and implausible trends and cross-country differentials. ${ }^{24}$ This is not to say that such inconsistencies do not exist in other reconstruction and projection exercises. Far from it. Yet, because it is almost impossible to convey the complexities of alternative projection models to the media, we feel that it is important to at least present our concerns on some of the key issues in the IHME exercise.

Our discussion began a non-systematic appraisal of concerns about fertility, mortality and migration scenarios in IHME exercise. In combination, we see the biggest failure in the lack of consistency and internal logic in the broader philosophy behind IHME projections and across different scenarios. Fertility, mortality and migration are projected using different models and underlying assumptions. Separately,

\footnotetext{
${ }^{24}$ Of potential concern is also the close partnership between IHME and The Lancet, which has become the key dissemination platform for the research produced by IHME and the GBD team (Mahajan 2019). This mutual collaboration may at times generate potential conflicts of interest, as in the case of the Lancet editor, dr. Richard Horton, receiving 2019 Roux Prize (a US $\$ 100,000$ award) for his accomplishments as one of the world's most "committed, articulate, and influential advocates for population health." The prize was administered by the IHME (IHME press release 10 June 2019). Clearly, such an intimate link between The Lancet and IHME may effectively limit critical scrutiny and discussion of the IHME work.
} 
these scenarios contain plenty of questionable and implausible results, often including contrasting and seemingly illogical trends between neighbouring countries. When combined, the whole projection does not hold well together and lacks a unifying framework and a more systematic perspective on human behaviour (see the discussion in Sanderson 1998). ${ }^{25}$ Specifically, the fertility, mortality and migration scenarios show major differences along the following dimensions:

- Model complexity and the number of underlying drivers considered, with fertility model based on two underlying factors (years of schooling and met need for contraceptive use) and mortality model based on modelling 274 causes of deaths;

- The lack of unifying key drivers (such as mean years of schooling, sustainable development, or climate change) across scenarios that would bring more consistency to the projection exercise;

- Differences in the projected trends in fertility, mortality and migration, with fertility often showing dynamic changes characterised by fast declines in high-fertility countries, whereas mortality and migration scenarios depict a subdued dynamics, implying a diminishing intensity of mortality improvements (and, eventually, stalling mortality) and declining average levels of net migration;

- Differences in the range of alternative scenarios, which are quite broad for fertility and relatively narrow for mortality. By contrast, only one (Reference) scenario has been computed for migration;

- Huge and often implausible and illogical differences in projected trends, scenarios and their confidence intervals across countries within broader regions ${ }^{26}$;

- Inconsistencies in the source data, which often considerably differ from the UNDP estimates that have often been used, as best-standard estimates of past population trends;

- Arbitrary decisions about the limiting levels of selected indicators (e.g., minimum level of completed cohort fertility set at one) and the absence of limits in other cases (no limit to maximum fertility level).

\footnotetext{
${ }^{25}$ At least three of the employed measures and indicators - an indicator of achieved level of education (mean years of schooling), the concept of sustainable development goals (SDGs), and the 'socio-demographic Index' (SDI) used in parts of the analysis-could have served to construct a broader narrative and connect different scenarios together. Given the missing unifying framework in the IHME projections, it is surprising their authors criticise other projections exactly for this perceived deficiency. For instance, they reckon there are only three 'structural scenarios' in the UNPD projections (p.2 in Vollset et al. 2020). In fact, there are nine (UNPD 2019). The authors claim that "neither the climate models nor the Wittgenstein Centre forecasts explicitly model the interrelationship between climate change and population" [p. 3] In fact, climate change is taken into account in the assumption designed both as part of the expert questionnaires for mortality (Garbero and Pamuk 2014; Caselli et al. 2014) and migration (Sander, Abel, and Riosmena 2014) and the explicit construction of 'alternative scenarios in the context of sustainable development' (which includes climate change) (KC and Lutz 2014).

${ }^{26}$ The contrasts in uncertainty intervals in projected fertility, mortality, migration and population between countries from broader regions, often sharing similar economic and cultural characteristics, are often so vast that they appear random. They rather resemble an outcome of an inexperienced player throwing darts on the target, randomly hitting closer or farther from the bullseye.
} 
These differences and inconsistencies are further magnified by a surprising deficit of demographic expertise in IHME team. As our colleague Peter McDonald (personal communication, 6 July 2020) dryly noted when commenting on retrospective global fertility data estimates by Murray et al. (2018), "None of the lead authors of the Lancet publication have any background in the analysis of fertility. None had published a previous paper on fertility. None of the almost 1,000 co-authors of the publication would be counted among the world's top 100 scholars of fertility measurement and estimation. In my assessment, this paper would never have been published by a leading demographic journal because of the inadequacy of its methods."

Our analysis has revealed many odd results across countries, with Iraq being identified as the frontrunner in several respects: an unstable country currently facing massive economic challenges, ethnic and territorial conflicts, is an unassuming mortality champion, expected to jump from aboutaverage mortality today to the fourth-highest female life expectancy in 2100 . Iraq is also expected to score high in net migration, with one of the highest projected net migration rates globally in midcentury. It is expected to see a massive population growth, which would be, with the exception of Israel, much faster than in other Middle East countries. What is unique about the country and its institutional setup to explain its distinct dynamics of mortality and migration? What will change in Iraq in the next decades? The example of Iraq illustrates the limits of IHME approach based on a sophisticated yet inconsistent 'play' with a massive amount of data: the vast number of underlying trends and indicators behind the IHME models makes it difficult or even impossible for the users to understand the logic behind the projected trends and results for individual countries. The logic of these results is often like a matrix or a black box: many of the key decisions, assumptions and underlying data are hidden or insufficiently explained. Migration crucially depend on the projected future death rates from conflict and violence-which are themselves extremely uncertain - but it is difficult to understand how are these and other underlying indicators modelled and derived.

Amid these inconsistencies, the IHME scenarios are relatively consistent in generating a picture of future rapid population declines across high-income countries with low fertility. It seems as if the IHME projection was designed to bring about this outcome. In contrast with the UNDP projection from 2019, the IHME scenarios are often based on different underlying data (e.g., implying a lower fertility in the base year 2017 in parts of Sub-Saharan Africa), they project lasting fertility falls to very low levels (and without any significant recovery in fertility in the subsequent period), they expect slowing-down in mortality improvements (and later a stagnation in life expectancy), and they envision much lower levels of net migration than recorded in the last two decades. Also, the fertility scenarios consider drivers that may reduce fertility in the future, such as unmet need for contraception, whereas they ignore factors which may eventually help fertility in low-fertility settings and among higher-educated couples to recover to higher levels, such as the evidence of higher desired family size, improved access to medically assisted reproduction or more family-friendly policies. Together, these scenarios suggest that regions like Southern Europe are on the verge of rapid and extensive depopulation, which might be an implausible outcome based on the assumptions applied. 
We suggested that the interpretation of the quantitative findings in both Vollset et al (2020) paper, and the manner in which they were represented to the media, can be perceived as problematic. In our discussion, we focused on issues relating to climate change, population decline and population ageing. Of course, the authors of the study cannot be blamed for the manner in which the media present their findings. But there are too many instances both in the paper itself, and in representations by the authors and IHME researchers to the media which appear to be gross oversimplifications and gloss over complex sociological, economic, scientific and political considerations.

Clearly, the new IHME projections have stimulated a great deal of interest in global population issues among both scholars and the general public. The coverage of the new projections has been quite literally 'global' in scope and in magnitude. Sometimes, however, the interpretation of the projections has been presented in a 'black and white' manner. The quotation at the start of this concluding section encapsulates this perspective of an overly simplistic, yet confident assertion of the findings of the study. When we start talking in simple terms about 'too many' or 'too few' people and warning about perceived implications and outcomes of such trends, we are beginning to traverse a dangerous path of demographic determinism. This path is well worn, and is littered with poorly conceived policy interventions which we must strive to avoid.

\section{References}

Adsera, Alicia. 2017. "Education and fertility in the context of rising inequality." Vienna Yearbook of Population Research 2017 (15): 63-92.

Al-Jazeera. 2020. "Population in More than 20 Countries to Halve by 2100: Study." Al-Jazeera. July 15, 2020. https://www.aljazeera.com/news/2020/07/population-20-countries-halve-2100-study200715061706992.html.

Alkema, Leontine. 2020. "The Global Burden of Disease fertility forecasts: Summary of the approach used and associated statistical concerns." Preprint 17 August 2020. DOI: 10.31219/osf.io/3m6va.

BBC. 2009. "Attenborough Warns on Population." BBC News. April 13, 2009. http://news.bbc.co.uk/2/hi/uk_news/7996230.stm.

Beaujouan, Éva and Caroline and Berghammer. 2019. "The gap between lifetime fertility intentions and completed fertility in Europe and the United States: A cohort approach." Population Research and Policy Review 38(4): 507-535.

Beckley, Michael. 2018. "The Power of Nations: Measuring What Matters." International Security 43 (2): 7-44.

Bongaarts, John. 2001. "Fertility and reproductive preferences in post-transitional societies." Population and Development Review 27: 260-81.

Bongaarts, John 2002. "The end of the fertility transition in the developed world". Population and Development Review 28 (3): 419-443.

Bongaarts, John. 2008. "Fertility transitions in developing countries: Progress or stagnation?" Studies in Family Planning, 39 (2): 105-110.

Bongaarts, John. 2017. "Africa's unique fertility transition." Population and Development Review, 43 (Supplement): 39-58.

Bongaarts, John and John Casterline. 2013. "Fertility transition: is sub-Saharan Africa different?" Population and Development Review 38 (Supplement 1): 153-168. 
Bongaarts, John and Christophe Z. Guilmoto. 2015. "How many more missing women? Excess female mortality and prenatal sex selection, 1970-2050." Population and Development Review 41(2): 241269.

Bricker, Darrell, and John Ibbitson. 2019. Empty Planet: The Shock of Global Population Decline. Hachette UK.

Caselli, Graziella, Sven Drefahl, Christian Wegner-Siegmundt, and Marc Luy. 2014. "Future Mortality in Low Mortality Countries." In World Population and Human Capital in the Twenty-First Century, edited by Wolfgang Lutz, William P. Butz, and Samir Kc, 226-72. Oxford: Oxford University Press.

Casterline, John, and Stuart Gietel-Basten. 2018. "Exploring Family Demography in Asia through the Lens of Fertility Preferences." In Family Demography in Asia. Edward Elgar Publishing.

Census and Statistics Department. 2017. Demographic Trends in Hong Kong 1986-2016. Kowloon, Hong Kong, Census and Statistics Department.

Chao, Fengqing, Patrick Gerland, Alex R. Cook, and Leontine Alkema. 2019. "Systematic assessment of the sex ratio at birth for all countries and estimation of national imbalances and regional reference levels." Proceedings of the National Academy of Sciences 116 (19): 9303-9311.

Chung, Woojin and Monica Das Gupta. 2007. "The decline of son preference in South Korea: The roles of development and public policy." Population and Development Review 33(4): 757-783.

Coleman, David, and Stuart Basten. 2015. "The Death of the West: An Alternative View." Population Studies 69 Suppl 1: S107-18.

Coleman, David, and Robert Rowthorn. 2011. "Who's Afraid of Population Decline? A Critical Examination of Its Consequences." Population and Development Review 37 (s1): 217-48.

Council of Europe. 2006. Recent Demographic Developments in Europe 2005. Strasbourg: Council of Europe Publishing.

Dick, P. I. 2016. "The Policy Pitfalls of Ageism. What Population Ageing Does and Does Not Mean for Society." Berlin: Population Europe.

Dorling, Danny. 2013. Population 10 Billion. Hachette UK.

Dorling, Danny, and Stuart Gietel-Basten. 2017. Why Demography Matters. Cambridge, UK: Polity Press.

Dynan, Karen, and Louise Sheiner. 2018. "GDP as a Measure of Economic Well-Being." Work. Pap 43. https://www.brookings.edu/wp-content/uploads/2018/08/WP43-8.23.18.pdf.

Emmott, Stephen. 2013. Ten Billion. Harmondsworth: Penguin.

Eurostat. 2020. Population and Social Conditions. Data on total fertility rates, accessed in August 2020 at https://ec.europa.eu/eurostat/data/database.

Ezeh, Alex, Frances Kissling, and Peter Singer. 2020. "Why Sub-Saharan Africa might exceed its projected population size by 2100." The Lancet, published online July 14, 2020. DOI: https://doi.org/10.1016/S0140-6736(20)31522-1 .

Gallagher, James. 2020. "'Jaw-Dropping' World Fertility Rate Crash Expected.” BBC, July 15, 2020. https://www.bbc.com/news/health-53409521.

Garbero, Alessandra, and Elsie Pamuk. 2014. "Future Mortality in High Mortality Countries." In World Population and Human Capital in the 21st Century2, 273-332. Oxford: Oxford University Press.

Giblin, Béatrice. 2013. "Economics and Geopolitics: A Relationship Worth (Re) Considering." Hérodote, no. 4: 3-11.

Gietel-Basten, S. 2016. "Why Brexit? The Toxic Mix of Immigration and Austerity." Population and Development Review 42 (4). https://doi.org/10.1111/padr.12007.

Gietel-Basten, S. A. 2019. The Population Problem in Pacific Asia. Oxford University Press.

Gietel-Basten, Stuart. 2018. "Reconceptualising Ageing for Comparative Analysis." Wirtschaftspolitische Blätter 2018 (1): 65-75.

Gietel-Basten, Stuart and Sergei Scherbov. 2020. "Exploring the 'true value' of replacement rate fertility." Population Research and Policy Review, 39 (4): 763-772. 
Gietel-Basten, S. A., T. Sobotka et al. 2020. "Letter on 'Fertility, Mortality, Migration, and Population Scenarios for 195 Countries and Territories from 2017 to 2100: A Forecasting Analysis for the Global Burden of Disease Study' by S. E. Vollset et Al. (published Online 14 July 2020; https://doi.org/10.1016/ )." https://osf.io/ytf6m/?view_only=5389a004f7e94917b30b5a4d4ea7a154.

Global Burden of Disease Health Financing Collaborator Network. 2019. "Past, Present, and Future of Global Health Financing: A Review of Development Assistance, Government, out-of-Pocket, and Other Private Spending on Health for 195 Countries, 1995-2050." The Lancet 393 (10187): 223360.

Gravelle, Timothy B. 2019. "Party Identification, Local Context, and Australian Attitudes toward Immigration and Asylum Policy." Social Science Research 81 (July): 77-90.

Gray, John. 2013. "Population 10 Billion by Danny Dorling and Ten Billion by Stephen Emmott." The Guardian 6.

Guilmoto, Christophe Z. and James Tove. 2015. "The masculinization of births. Overview and current knowledge." Population 70 (2): 185-243.

Guo, Zhigang, Gietel-Basten, Stuart and Gu, Baochang. 2019. "The lowest fertility rates in the world? Evidence from the 2015 Chinese 1\% sample census." China Population and Development Studies 2 (3): 245-258.

He, Dan, Xuying Zhang, Ya'er Zhuang, Zhili Wang, Yu Jiang. 2019. “China fertility report, 2006-2016. An analysis based on China fertility survey 2017." China Population and Development Studies 2 (4): 430-439.

Human Fertility Database. 2020. Max Planck Institute for Demographic Research (Germany) and Vienna Institute of Demography (Austria), accessed in August 2020 at www.humanfertility.org.

IHME Press Release 10 June 2019. "The Lancet editor Richard Horton honored with Roux Prize." Available at http://www.healthdata.org/news-release/lancet-editor-richard-horton-be-honoredjune-10.

Ivković, Anita Frajman. 2016. "LIMITATIONS OF THE GDP AS A MEASURE OF PROGRESS AND WELLBEING." Ekonomski vjesnik/Econviews - Review of Contemporary Business, Entrepreneurship and Economic Issues 29 (1): 257-72.

Jalovaara, Marika, Gerda Neyer, Gunnar Andersson, Johan Dahlberg, Lars Dommermuth, Peter Fallesen and Trude Lappegård. 2019. "Education, gender, and cohort fertility in the Nordic countries." European Journal of Population 35 (3): 563-586.

Kantorová, Vladimíra, Mark C. Wheldon, Philipp Ueffing, and Aisha NZ Dasgupta. 2020. "Estimating progress towards meeting women's contraceptive needs in 185 countries: A Bayesian hierarchical modelling study." PLoS Medicine 17, No. 2 (2020): e1003026.

KC, Samir, and Wolfgang Lutz. 2014. "Alternative Scenarios in the Context of Sustainable Development." In World Population and Human Capital in the Twenty-First Century, 591-627. Oxford: Oxford University Press.

Kebede, Endale, Anne Goujon, and Wolfgang Lutz. 2019. "Stalls in Africa's fertility decline partly result from disruptions in female education." PNAS 116 (8): 2891-2896.

Kokabisaghi, Fatemeh. 2017. "Right to Sexual and Reproductive Health in New Population Policies of Iran." Journal of Public Health Policy 38 (2): 240-56.

Komine, Ayako. 2018. "A Closed Immigration Country: Revisiting Japan as a Negative Case." International Migration 56 (5): 106-22.

KOSIS. 2020. Total Fertility Rates and Age-Specific Fertility Rates for city, county, and district. Statistics Korea, vital statistics database accessed 10 August 2020 at http://kosis.kr.

Last, Jonathan. 2013. What to Expect When No One's Expecting: America's Coming Demographic Disaster. New York, NY: Encounter Books. 
Lee, Ronald. 2003. "The demographic transition: three centuries of fundamental change." Journal of Economic Perspectives, 17(4), 167-190.

Lee, Ronald Demos, and Andrew Mason. 2012. Population Aging and the Generational Economy : A Global Perspective. Cheltenham: Edward Elgar.

Lee, Ronald, Andrew Mason, and members of the NTA network. 2014. "Is low fertility really a problem? Population aging, dependency, and consumption." Science 346 (6206): 229-234.

Longman, Phillip. 2004. The Empty Cradle: How Falling Birthrates Threaten World Prosperity and What To Do About It. New York: Basic Books.

Lutz, Wolfgang. 1987. "Finnish fertility since 1722: lessons from an extended decline." Finnish Population Research Institute.

Lutz, Wolfgang. 2013. "Demographic Metabolism: A Predictive Theory of Socioeconomic Change." Population and Development Review 38 (s1): 283-301.

Lutz, Wolfgang, William P. Butz and Samir K.C. (eds.) 2014. World Population and Human Capital in the 21st Century. Oxford: Oxford University Press

Lutz, Wolfgang, Anne Goujon, Samir KC, Marcin Stonawski, and Nikolaos Stilianakis. 2018. Demographic and Human Capital Scenarios for the 21st Century: 2018 assessment for 201 countries. Luxembourg: Publications Office of the European Union.

MacFarlane, Katrina A., Mary Lou O’Neil, Deniz Tekdemir, Elvin Çetin, Barış Bilgen, and Angel M. Foster. 2016. "Politics, Policies, Pronatalism, and Practice: Availability and Accessibility of Abortion and Reproductive Health Services in Turkey." Reproductive Health Matters 24 (48): 62-70.

MacKellar, F. Landis, Wolfgang Lutz, Christopher Prinz, and Anne Goujon. 1995. "Population, Households, and CO2 Emissions." Population and Development Review 21(4): 849-65.

Mahajan, Manjari. 2019. "The IHME in the shifting landscape of global health metrics." Global Policy, 10 (2019): 110-120.

Mason, Andrew, and Ronald Lee. 2006. "Reform and Support Systems for the Elderly in Developing Countries: Capturing the Second Demographic Dividend." Genus 62 (2): 11-35.

McDonald, Peter, and Andrew Markus. 2020. "It Is All about Race and Immigration: Population and Politics in Australia and New Zealand." In Global Political Demography: The Politics of Population Change, edited by Pieter Vanhuysse and Achim Goerres. London: Palgrave.

Meredith, Sam. 2020. "Falling Fertility Rates to Trigger 'Major Shifts' in Economic Power, Research Predicts." CNBC. CNBC. July 15, 2020. https://www.cnbc.com/2020/07/15/world-populationfalling-fertility-rates-to-create-major-shifts-in-economic-power.html.

Morgan, S. Philip, Zhigang, Guo and Hayford, Sarah R. 2009. "China's below-replacement fertility: Recent trends and future prospects." Population and Development Review 35(3): 605-629.

Murray, Christopher JL, Charlton SKH Callender, Xie Rachel Kulikoff, et al. 2018. "Population and fertility by age and sex for 195 countries and territories, 1950-2017: a systematic analysis for the Global Burden of Disease Study 2017." The Lancet 392 (10159): 1995-2051.

OECD. 2017. The Pursuit of Gender Equality: An Uphill Battle. Paris: OECD Publishing.

OECD. 2011. Doing Better for Families. Paris: OECD Publishing.

Oeppen, Jim and Vaupel, James W. 2002. "Broken limits to life expectancy." Science 296 (5570): 10291031.

O’Neill, Brian C., Michael Dalton, Regina Fuchs, Leiwen Jiang, Shonali Pachauri, and Katarina Zigova. 2010. "Global Demographic Trends and Future Carbon Emissions." PNAS 107 (41): 17521-26.

O'Sullivan, Jane. 2020. "Will global population peak below 10 billion?" Blogpost, The Overpopulation Project, July 27, 2020. https://overpopulation-project.com/will-global-population-peak-below-10billion/.

Paúl, Constança, Oscar Ribeiro, and Laetitia Teixeira. 2012. "Active Ageing: An Empirical Approach to the WHO Model." Current Gerontology and Geriatrics Research 2012 (October): 382972. 
Pendleton, Brian F. 1978. "An Historical Description and Analysis of Pronatalist Policies in Italy, Germany and Sweden." Policy Sciences 9 (1): 45-70.

Recknagel, Charles. 2015. "Bosnia erupts in feuding over new census data." Radio Free Europe, 30 June 2016; https://www.rferl.org/a/bosnia-census-results-spark-feuding/27831183.html.

Roberts, Glenda S. 2018. "An Immigration Policy by Any Other Name: Semantics of Immigration to Japan." Social Science Japan Journal 21 (1): 89-102.

Safi, Michael. 2020. "Year 2100: Countries Warned to Prepare for 50\% Fall in Population." The Guardian, July 25, 2020.

Sander, Nikola, Guy J. Abel, and Fernando Riosmena. 2014. "The Future of International Migration." In World Population and Human Capital in the Twenty-First Century, edited by Wolfgang Lutz, William P. Butz, and Samir Kc, 333-96. Oxford: Oxford University Press.

Sanderson, Warren C. 1998. "Knowledge can improve forecasts: A review of selected socioeconomic population projection models." Population and Development Review, Suplement to Vol. 24: 88117.

Sanderson, Warren C., and Sergei Scherbov. 2015. "Are We Overly Dependent on Conventional Dependency Ratios?" Population and Development Review 41 (4): 687-708.

-- - 2019. Prospective Longevity: A New Vision of Population Aging. Harvard University Press.

Sanyal, S. 2011. "The End of Population Growth." London: Deutsche Bank.

Shapiro, David and Tesfayi Gebreselassie. 2008. "Fertility transition in sub-Saharan Africa: falling and stalling." African Population Studies 23 (1): 3-23.

Shapiro, David and Andrew Hinde. 2020. "Laggards in the global fertility transition." Vienna Yearbook of Population Research 18 (2020) (forthcoming).

Sobotka, Tomáš, Éva Beaujouan, and Jan Van Bavel. 2017. "Introduction: Education and fertility in lowfertility settings." Vienna Yearbook of Population Research, 15 (2017): 1-16.

Sobotka, Tomáš. 2017. "Post-transitional fertility: the role of childbearing postponement in fuelling the shift to low and unstable fertility levels." Journal of Biosocial Science 49 (S1): S20-S45.

Stiglitz, J. E. 2009. "GDP Fetishism." The Economists' Voice. https://www.degruyter.com/downloadpdf/journals/ev/6/8/article-ev.2009.6.8.1651.pdf.pdf.

Thévenon, Olivier. 2011. "Family Policies in OECD Countries: A Comparative Analysis." Population and Development Review 37 (1): 57-87.

Tin-yau, Ko. 2018. "China Academics Suggest 'no-Child Tax' to Boost Fertility Rate." EJ Insight. August 22, 2018. http://www.ejinsight.com/20180822-china-academics-suggest-no-child-tax-to-boostfertility-rate/.

UNDESA-UNPD. 2019. "World Population Prospects 2019: Methodology of the United Nations Population Estimates and Projections." ST/ESA/SER.A/425. United Nations Department of Economic and Social Affairs; Population Division.

UNPD. 2001. "Replacement Migration: Is It a Solution to Declining and Ageing Populations?" UNPD. 2001. https://www.un.org/en/development/desa/population/publications/ageing/replacementmigration.asp.

- - - 2019. "World Population Prospects: The 2019 Revision." United Nations, Department of Economic and Social Affairs, Population Division. https://population.un.org/wpp/Download/Standard/.

- - . 2019a. File INT/1: Interpolated demographic indicators by region, subregion and country, annually for 1950-2099. United Nations, Department of Economic and Social Affairs, Population Division. World Population Prospects 2019, Online Edition. Rev. 1.

- - . 2019b. Estimates and Projections of Family Planning Indicators 2019. New York: United Nations, Department of Economic and Social Affairs, Population Division.

VID. 2020. European Demographic Datasheet 2020. Vienna Institute of Demography, IIASA, Wittgenstein 
Centre for Demography and Global Human Capital. www.populationeurope.org.

Vollset, Stein Emil, Goren, Emily, Yuan, Chun-Wei, Cao, Jackie, Smith, Amanda E., Hsiao, Thomas, Bisignano, Catherine et al. 2020. "Fertility, mortality, migration, and population scenarios for 195 countries and territories from 2017 to 2100: a forecasting analysis for the Global Burden of Disease Study." The Lancet (in press); https://doi.org/10.1016/S0140-6736(20)30677-2.

Wallace, Paul. 2001. Agequake: Riding the Demographic Rollercoaster Shaking Business, Finance and Our World. London: Nicholas Brealey Publishing.

Wittgenstein Centre. 2018. Wittgenstein Centre Data Explorer Version 2.0 (Beta). Wittgenstein Centre for Demography and Global Human Capital. Accessed 10 August 2020 at http://www.wittgensteincentre.org/dataexplorer.

WHO. 2018. "What Is Healthy Ageing?" Ageing and Life-Course. World Health Organization. February 8, 2018. https://www.who.int/ageing/healthy-ageing/en/.

Woodyatt, Amy. 2020. "World's Population Likely to Shrink after 50 Years." CNN, July 14, 2020. https://www.cnn.com/2020/07/14/world/world-population-shrink-intl-scli-scn/index.html. 